\title{
Flame retarded poly(lactic acid): A review
}

\author{
W. S. Chow ${ }^{*}$, E. L. Teoh ${ }^{1}$, J. Karger-Kocsis ${ }^{2}$ \\ ${ }^{1}$ School of Materials and Mineral Resources Engineering, Engineering Campus, Universiti Sains Malaysia, Nibong Tebal, \\ 14300 Penang, Malaysia \\ ${ }^{2}$ Department of Polymer Engineering, Faculty of Mechanical Engineering, Budapest University of Technology and \\ Economics, Megyetem rkp. 3., H-1111 Budapest, Hungary
}

Received 17 October 2017; accepted in revised form 11 December 2017

\begin{abstract}
Poly(lactic acid) (PLA) synthesized from renewable resources has drawn a great deal of interest in packaging, electronics and automotive applications. However, poor flame retardancy of PLA, especially its ease of ignitability and heavily flaming drips, represents a major obstacle for its potential application. The article outlines the recent advances in the field of flame-retarded PLA. Current development trends based on the direct incorporation of flame retardant additives, chemical modification, hybridization and synthesis of flame retardants were reported. Results obtained from UL 94 vertical burning, limiting oxygen index (LOI) and cone calorimetry (CCM) tests for each type of flame retardants were discussed and analyzed. Test results summarized in a UL 94-LOI matrix found to be a useful tool to determine the effectiveness of flame retardants in PLA. The UL 94-LOI comparison matrix and CCM test results revealed that the combined use of flame retardants (containing intumescent formulation) is one of the promising strategies to reach the flame retardancy of PLA needed by practical applications. This review ends with a brief summary of and outlook on future developments of flameretarded PLA systems.
\end{abstract}

Keywords: biopolymers, poly(lactic acid), flame retardancy

\section{Introduction}

\subsection{Poly(lactic acid)}

Nowadays, biodegradable polymers derived from natural resources are receiving more and more attention due to increasing environmental awareness because of the negative impact of excessive use of petrochemical-based polymers. One of the polymers from renewable resources, thermoplastic poly(lactic acid) (PLA), has successfully reached commercial-scale production, and experienced rapid market penetration in recent years [1]. The stereochemical composition of the lactic acids and lactides (dimer produced by dehydration and preferentially used to synthesize PLA via ring-opening polymerization) strongly affect the thermomechanical properties of the resulting PLAs $[2,3]$. As commercial PLA products are mostly poly(L-lactide)s, no difference will be made between the various PLA stereoisomers. The excellent properties of PLA including good mechanical properties (i.e., high modulus and strength), biocompatibility (extensively exploited in medical applications [4, 5]), high transparency, low toxicity, and flexible processability are comparable with those of some traditional petroleum-based thermoplastics [6-8]. Among the disadvantages of PLA are its low ductility [9], low toughness [10], low nucleation/ crystallization rates $[11,12]$ associated with massive physical aging [13] and ease of ignitability. PLA offers several advantages over 'petroresins'. The production of PLA involves far less fossil fuel energy and greenhouse gas emissions than the production of conventional petrochemical-based polymers [1416]. Moreover, PLA offers additional waste management routes such as composting, chemical recycling

*Corresponding author, e-mail: shyang@usm.my (C) BME-PT 
and anaerobic digestion. PLA is introduced into the natural life cycle through composting, by means of biodegradation, thereby improving the quality of the soil. Besides, post-consumer PLA materials can be hydrolyzed to lactic acid, which is the feedstock for the production of lactide, ethyl lactate, other lactic derivatives and even PLA [14, 17, 18]. Last, but not least, PLA burns with a clean blue flame without producing any corrosive or toxic gases [19]. Table 1 describes possible end-of-life options for PLA [20]. PLA is gaining market acceptance and has the possibility to replace traditional petroleum-based thermoplastics if its properties are matched with other thermoplastics. Producers claimed that PLA has the potential to partially replace poly(methyl methacrylate) (PMMA), poly(amide) (PA), poly(ethylene terephthalate) (PET), as well as poly(propylene) (PP) in various applications [21-23]. Its favorable physical properties (i.e., good mechanical properties, high degree of transparency, and low toxicity) and its
Table 1. Possible waste management approaches for petrochemical-based polymers and PLA, respectively [20].

\begin{tabular}{|l|c|c|}
\hline End-of-life options & $\begin{array}{c}\text { Petrochemical-based } \\
\text { polymers }\end{array}$ & PLA \\
\hline Landfill & + & + \\
\hline Mechanical recycling & + & + \\
\hline Incineration & + & + \\
\hline Composting & - & + \\
\hline Anaerobic digestion & - & + \\
\hline Chemical recycling & \pm & + \\
\hline
\end{tabular}

Remarks:

+ Possible waste disposal form

- Impractical waste disposal form

\pm Only useful for certain petrochemical-based polymers

(i.e. poly(ethylene terephthalate), PET).

processability on conventional equipment make PLA suitable for a broad range of applications. Table 2 summarizes the current applications along with the 'functional' properties of PLA in various sectors [24-28].

Table 2. Applications of PLA in various sectors with functional properties and products available in market.

\begin{tabular}{|c|c|c|c|}
\hline Sectors & Commercially available applications & Functional property & Examples \\
\hline Packaging & $\begin{array}{l}\text { - food packaging } \\
\text { - films } \\
\text { - rigid thermoformed food and bever- } \\
\text { age containers } \\
\text { - carrier bags and labels } \\
\text { - coated papers and boards } \\
\text { - battery packaging }\end{array}$ & $\begin{array}{l}\text { - high stiffness } \\
\text { - twist retention } \\
\text { - high clarity } \\
\text { - low temperature sealability } \\
\text { - flavor, aroma and grease resistance } \\
\text { - Generally recognized as safe status } \\
\quad[14]\end{array}$ & $\begin{array}{l}\text { - Wild Oats uses PLA in its food prod- } \\
\text { ucts packaging [14] } \\
\text { - Pioneered use in yogurts cup and cut- } \\
\text { lery by Dannon and McDonald's } \\
\text { (Germany) [24]. }\end{array}$ \\
\hline $\begin{array}{l}\text { Fibers and } \\
\text { fabrics }\end{array}$ & $\begin{array}{l}\text { - pillows, mattresses and duvets } \\
\text { - apparels } \\
\text { - floor, wall and furniture textiles }\end{array}$ & $\begin{array}{l}\text { - stain resistance } \\
\text { - good moisture management } \\
\text { - good flame resistance } \\
\text { - low odor retention } \\
\text { - good loft, resilience and comfort } \\
\text { - shape retention } \\
\text { - crease resistance [14] }\end{array}$ & $\begin{array}{l}\text { - Use in teabag filters and coffee filter } \\
\text { webs }\left(\text { Bioweb }{ }^{\circledR}\right) \text { by Ahlstrom [25]. } \\
\text { - Kanebo, Inc. introduced PLA fiber } \\
\text { under the trade name of Lactron } \\
\text { fiber at February } 1998 \text { Nagano Winter } \\
\text { Olympics [17]. }\end{array}$ \\
\hline Agriculture & $\begin{array}{l}\text { - encapsulation matrix for herbicides } \\
\text { - weed penetration nets and vegetable } \\
\text { nets } \\
\text { - sandbags } \\
\text { - vegetable pots }\end{array}$ & $\begin{array}{l}\text { - biodegradability } \\
\text { - controlled released during service } \\
\text { time } \\
\text { - readily undergoes hydrolytic degra- } \\
\text { dation }\end{array}$ & $\begin{array}{l}\text { - Chang et al. [26] had evaluated the } \\
\text { potential of PLA in encapsulation ma- } \\
\text { trix for controlled release of herbi- } \\
\text { cides application. }\end{array}$ \\
\hline Transportation & $\begin{array}{l}\text { - floor mat } \\
\text { - spare tire covers } \\
\text { - head liners } \\
\text { - outer skin material for door trim }\end{array}$ & $\begin{array}{l}\text { - light in weight } \\
\text { - improve in thermal resistance } \\
\text { - improve in moisture resistance } \\
\text { - improve in impact resistance } \\
\text { - improve in resistance to weathering }\end{array}$ & $\begin{array}{l}\text { - Toyota has introduced spare tire cover } \\
\text { consisted of kenaf-PLA composite } \\
\text { with improve impact resistance [27]. }\end{array}$ \\
\hline $\begin{array}{l}\text { Electric appli- } \\
\text { ances and } \\
\text { electronics }\end{array}$ & $\begin{array}{l}\text { - compact disc } \\
\text { - computer keys } \\
\text { - chassis for portable audio player } \\
\text { - wrappers for compact disc }\end{array}$ & $\begin{array}{l}\text { - improved flame resistant } \\
\text { - improve in thermal resistant } \\
\text { - improve in impact resistance }\end{array}$ & $\begin{array}{c}\text { - Chassis of notebook personal com- } \\
\text { puter made of PLA/PC/phosphorus } \\
\text { flame retardant agents by Fujitsu [27]. } \\
\text { - Sony utilized PLA to make chassis for } \\
\text { portable audio player 'Walkman' [27]. }\end{array}$ \\
\hline Building & $\begin{array}{l}\text { - expandable foams } \\
\text { - carpet tiles } \\
\text { - moquettes }\end{array}$ & $\begin{array}{l}\text { - excellent insulation } \\
\text { - high compressive strength } \\
\text { - moisture resistant } \\
\text { - resistant to pests, fungi and bacteria }\end{array}$ & $\begin{array}{l}\text { - Expandable foam made of PLA with } \\
\text { trade name BioFoam }{ }^{\circledR} \text { developed by } \\
\text { Synbra Technology in the collabora- } \\
\text { tion with Sulzer Chemtech and Purac } \\
\text { Biochem [28]. }\end{array}$ \\
\hline
\end{tabular}




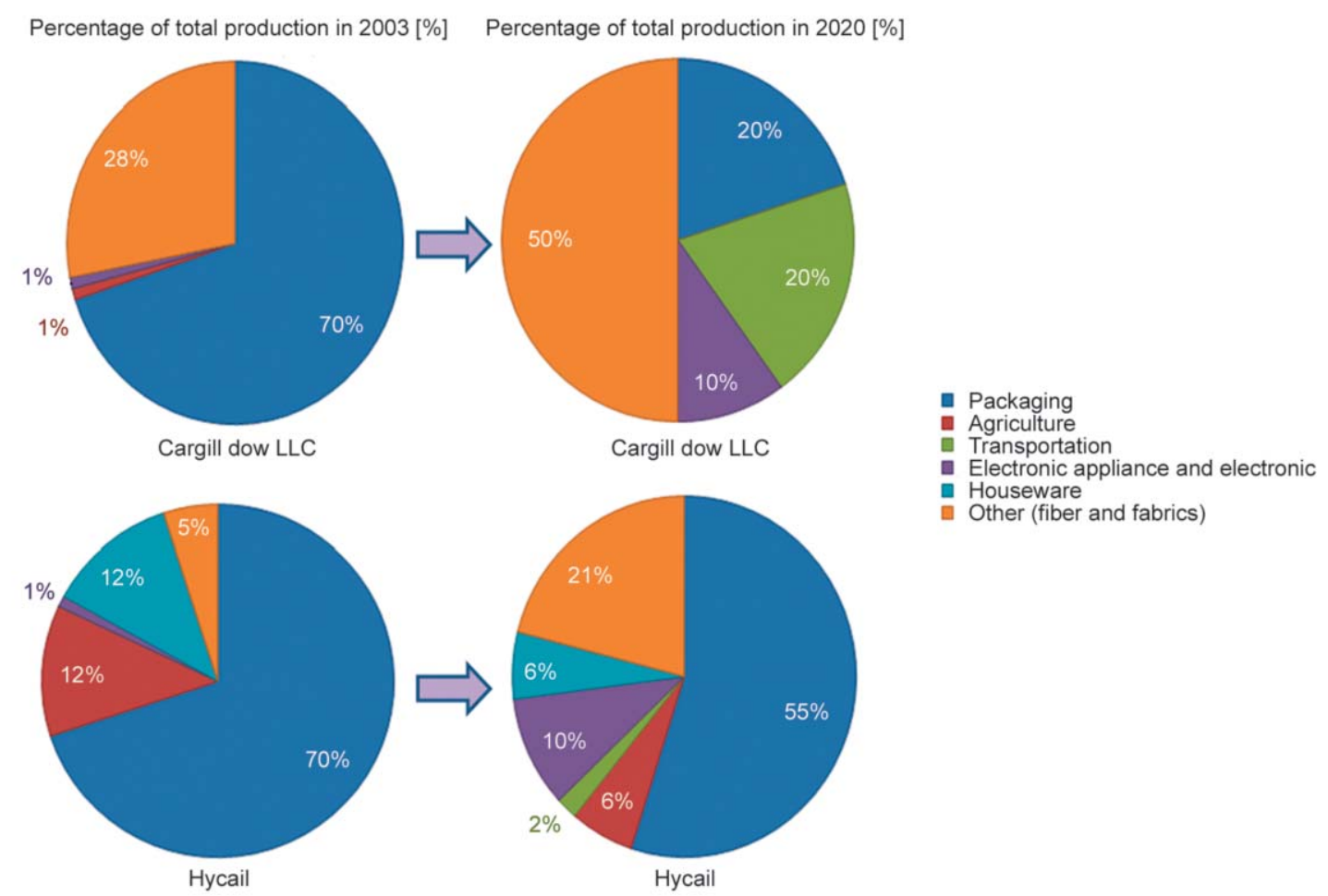

Figure 1. Current and estimation of future market and applications of PLA in various sectors [22].

Based on an estimation of the current and future market share of PLA (c.f. Figure 1), it can be stated that PLA is mostly used in packaging today (ca. of $70 \%$ of the total production of PLA). The use of PLA is expected to grow in further areas of application, such as textiles, transportation and electronics by 2020 . This means that in the future not only the biodegradability of PLA, but also its excellent performance will be exploited. Considering the possible engineering applications of PLA, its flame retardancy, as well as its toughness, should be a primary target of research and development.

\subsection{Applications of flame-retarded poly(lactic acid)}

The potential of PLA for electronic housing applications was recognized early. In 2005, Fujitsu successfully developed a flame-proof PLA-based material for the housing of notebook computers. With the incorporation of either $5 \mathrm{wt} \%$ methylphenyl-silicone resin or $20 \mathrm{wt} \%$ aluminum hydroxide $\left(\mathrm{Al}(\mathrm{OH})_{3}\right)$ in PLA, the $\mathrm{V}-2$ rating of the UL-94 standard test was reached [29]. The notebook model (FMV-BIBLIO NB80-K) based on PLA was released by Fujitsu in Japan in mid-2007, and worldwide in 2008 [30, 31]. One of the world's leading providers of broadband and mobile internet solutions, NEC Corporation, has successfully developed a flame-retardant biodegradable PLA resin. This resin contains no toxic halogen or phosphorus flame retardants, and is rated UL-94 $5 \mathrm{~V}$ and UL-94 V-0 (1.6 mm specimen thickness). Instead, a metal hydroxide-based flame retardant (aluminum hydroxide, which absorbs heat during ignition) was added to achieve the above rating. Other additives were also added in order to ensure that the PLA has heat resistance, moldability and strength comparable to those of fiber-reinforced polycarbonate (PC), which is traditionally used in desktop-type electronic products [32]. Recently, NEC began to apply flame-retarded PLA for internal components of outdoor gas station fueling systems. This was possible due to the development of an oil- and chemical-resistant flameretarded PLA exhibiting enhanced dimensional stability [33]. Such developments encouraged researchers to focus on the development of flame-resistant PLA compounds.

\section{Flame retardancy of poly(lactic acid)}

Most flammability evaluation results showed that PLA is quite flammable without the incorporation of FRs (i.e., fails to be ranked in the UL-94 vertical burning test and exhibits LOI values of 19-21\%). The poor fire performance of PLA, especially high ignitability and flaming drips, might lead to a rapid spread of flame in a fire scenario. Therefore, the development flame-retarded PLA is an important and 
challenging task. Various methods for improving the flame retardancy of PLA have already been reviewed by Bourbigot and Fontaine [34]. The authors reported that the incorporation of FRs into polymer through conventional thermoplastic processing is the most straightforward strategy to produce PLA with improved properties. The steep increase in the number of research papers focusing on decreasing the flammability of PLA forced us to provide the reader with an updated review on flame-retardant PLA compounds.

\subsection{Poly(lactic acid) with phosphorus and hypophosphite based flame retardant}

Wei et al. [35] studied the effect of phosphorus-based FR on the burning behavior of flame-retarded PLA systems. An aryl polyphenylphosphonate, poly(9oxa-10-(2,5-dihydro-xyphenyl) phospha-phenanthrene-10-oxide) phenylphosphonate (WLA-3), was added to PLA by direct melt compounding. The presence of 7 parts per hundred resin (phr) WLA-3 was sufficient to provide PLA with self-extinguishing properties, achieving $\mathrm{V}-0$ rating with a LOI value of $25 \%$. The CCM test showed a slight reduction in PHRR with prolonged TTI, which suggested that WLA-3 could accelerate the degradation of PLA to low molecular weight compounds through the release of its acidic compounds. This was associated with a pronounced flow of the polymer and thus with a departure of the burning surface under the influence of the flame. Besides, gas-phase mechanisms are also at work during burning, which contribute to the inhibition of flame growth.

Being inspired by the reported flame retardant action of aluminum hypophosphite and rare earth oxide, Tang et al. [36] synthesized two types of rare earth hypophosphite (REHP): lanthanum hypophosphite (LaHP) and cerium hypophosphite (CeHP) to improve the flame retardancy of PLA. With the addition of $30 \mathrm{wt} \%$ LaHP and CeHP in PLA, similar LOI values were achieved (i.e., 28.5\%) with $\mathrm{V}-0$ rating in the UL 94V burning test. The temperature at the PHRR also slightly increased with the incorporation of LaHP and CeHP, possibly due to the degradation products of REHP. Phosphate and pyrophosphate are stable at high temperatures, forming an effective physical barrier that suppresses heat and mass exchange between the environment and the materials. Lower intensity was detected on the PLA/REHP composites compared to neat PLA in thermogravimetric analysis-infrared spectroscopy (TGA-IR) analysis. TGA-IR measurement suggested that the existence of a compact char layer as a result of the REHP decomposition reduced the decomposition rate of PLA and prohibited gas diffusion. In a companion paper Tang et al. [37] explored the efficiency of calcium hypophosphite (CaHP) as a FR additive in PLA. The LOI value of the PLA composite with $30 \mathrm{wt} \% \mathrm{CaHP}$ loading was improved to $26.5 \%$ compared with $19.5 \%$ of the virgin PLA. The UL 94 test indicated that this PLA-FR composite would pass the V-0 rating compared to no rating of pure PLA.

\subsection{Poly(lactic acid) with intumescent flame retardant}

Using intumescent flame retardants (IFR) is another promising way to enhance the fire performance of PLA due to its advantages, such as less smoke production, low toxicity, low corrosion, and no molten PLA dripping when burning [38, 39]. However, the high water uptake/solubility of the conventional charring agent pentaerythritol (PER) disqualified its use for durable and engineering applications [40]. Thus, the development of environmentally friendly carbonization agents that can replace PER in IFR is the focus of current studies.

Réti et al. [41] investigated the effectiveness of lignin and potato starch - both from renewable resources - in substituting PER as a carbonization agent in the presence of ammonium polyphosphate (APP). The basic idea was to make an intumescent PLA with the highest percentage of bio-based ingredients. The interesting feature displayed by both bio-based systems was the V-0 classification in the UL-94 test, while the reference formulation PLA/APP/PER yielded a V-2 classification. These results underline the fact that the formation and structure of the intumescent layer is a key parameter to protect the material beneath because it limits the heat and mass transfers when IFR/polymer formulations are burned. Zhang et al. [40] prepared urea-modified lignin (UM-Lig) according to the Mannich reaction and added ammonium polyphosphate (APP) as a novel IFR to PLA. The PLA/UM-Lig/APP composite successfully achieved $\mathrm{V}-0$ in the UL-94 vertical burning test, with a LOI value of $34.5 \%$, and with a sharp decrease in PHRR and THR in the CCM test. This suggested that UMLig has excellent charring ability when combined with APP. The continuous, swollen, dense char layer forming on the specimen surface during combustion 
prevented the further degradation of the underlying substrate.

Besides, the traditional carbonization agent, pentaerythritol (PER), was replaced by $\beta$-cyclodextrin (CD), a starch-based product, in an intumescent flame retardant (IFR) for PLA in a research study conducted by Feng et al. [42]. The flame retardancy and charforming ability of the IFR were evaluated at different weight ratios of $\mathrm{CD}$ with the acid source ammonium polyphosphate (APP) and/or blowing agent melamine (MA). Thermogravimetric analysis (TGA) proved that all APP/MA/CD combinations doubled the char residue in a nitrogen atmosphere compared to the data calculated with the sum of the single components. Among all IFR PLA composites which were rated UL-94 V-0, the APP/MA/CD with weight ratios of $1 / 2 / 1$ showed the best performance exhibiting an LOI value of $34.2 \%$. Such findings point to the interaction between $\mathrm{CD}$ and $\mathrm{APP}$, or $\mathrm{CD}$ and MA, which supports char formation during degradation.

Higher charring ability and better flame retardant properties were found for PLA by Wang et al. [43] when polypseudorotaxane (PPR) was introduced as a 'green' carbon source in an IFR formulation containing APP and MA. PPR is an inclusion complex between $\mathrm{CD}$ and poly(propylene glycol) (PPG). The authors demonstrated that the thermal stability of PLA/APP/MA/PPR (weight ratio of APP/MA/PPR = $2 / 1 / 1$ ) was the highest among all the IFR systems in both nitrogen and air. The LOI value of the PLA/ APP/MA/PPR composite with the UL-94 V-0 rating was $34 \%$, which is higher than the LOI value exhibited by the combined use of PPG and CD (i.e., $30.5 \%)$.

Other than lignin and starch, nanofibrillated cellulose fibers (NFC), POSS-modified cellulose (PNFC), and rice hull flour (RHF) were used as natural carbon sources for IFR formulations by Fox et al. [44]. These natural carbon sources were added in combination with APP to improve the FR properties of PLA. It was reported that all the PLA composites with $15 \mathrm{wt} \%$ IFR showed excellent flame retardancy in the UL-94 burning test (i.e., V-0 rating), regardless of the carbon source(s) used. According to another study of Fox et al. [45], both APP/NFC and APP/ PNFC yielded remarkable reduction in the PHRR and THR during CCM experiments through extensive char formation. This indicates that NFC and PNFC may be effective natural carbon sources in IFR formulations.
A charring agent has been synthesized to solve the low char-forming ability and serious dripping phenomenon found in PLA. Yuan et al. [46] used different ratios of tris(2-hydroxyethyl) isocyanurate (THEIC) and terephthalic acid (TPA) to synthesize charring agents for IFR. The performance of two types of charring agents based on tris (2-hydrooxyethyl) isocyanurate terephthalic acid ester (viz. dimer/ trimer mixture TT23 and tetramer TT4) was compared in IFR formulations containing APP. It was found that the overall fire performance of PLA/APP/ TT4 is better than PLA/APP/TT23 in terms of UL94 vertical burning, LOI and CCM tests. Such a difference in FR performance can be traced to the molecular build-up of charring agents, where larger molecular weight or a high degree of polymerization are preferable. TT4 with larger molecular weight and a higher degree of polymerization than TT23 tends to produce high-quality char the structure of which offers a powerful protection to the PLA composite from further burning.

Zhan et al. [47] synthesized an IFR, spirocyclic pentaerythritol bisphosphorate disphosphoryl melamine (SPDPM), from spirocyclic pentaerythritol bisphosphorate disphosphoryl chloride (SPDPC) and melamine to improve the fire performance of PLA. The introduction of SPDPM significantly enhanced the flame retardancy and reduced the dripping of PLA. Interestingly, UL-94 V-0 rating was achieved for PLA which contained $25 \mathrm{wt} \%$ SPDPM (PLA/ 25SPDPM). In addition, the reduction of heat release capacity (HRC) was observed in a microscale combustion calorimeter (MCC) for PLA containing SPDPM. SPDPM was involved in the formation of an intumescent char layer that covered the surface of the material and thus prevented the inner substrates from further degradation.

Wang et al. [38] prepared intumescent flame-retarded PLA/starch biocomposites by incorporating microencapsulated ammonium polyphosphate (MCAPP) and melamine (MA). The polyurethane encapsulation wall improved the compatibility between MCAPP and PLA while restraining the reaction between APP and starch during processing. With the presence of MCAPP and MA in a total of $20 \mathrm{wt} \%$ (i.e., a weight ratio of 2:1), the PLA/starch composite successfully achieved UL-94 V-0 rating along with an LOI of $41 \%$. Besides, less flammable gas was released by the formulation during combustion according to the TGAIR analysis. These findings point to the formation of 
an intumescent char layer inhibiting heat transfer and preventing the polymer substrate from further degradation.

Ke et al. [48] prepared a novel hyperbranched polyamine containing triazine units, which was used as a charring agent in an intumescent formulation together with APP. The optimum ratio of APP to this hyperbranched polyamine was $3: 2$. When IFR content was $30 \mathrm{wt} \%$, the corresponding PLA exhibited an LOI value of $36.5 \%$ and a V-0 rating. The PHRR and THR values obtained from cone calorimeter tests were reduced drastically compared to pure PLA and the PLA/APP system. The PLA even with a total loading of $15 \mathrm{wt} \%$ IFR passed the UL $94 \mathrm{~V}-0$ rating. TGA demonstrated a synergistic effect between the polyamine and APP with respect to charring.

\subsection{Poly(lactic acid) with nanofiller as flame retardant}

It is important to note that nanoscale particulates of various aspect ratios confer significant property improvements at relatively low concentrations, while traditional microparticle additives require much higher loading levels to achieve similar performance. This is possibly due to the large surface area of nanoscale materials compared to microscale materials, resulting in a higher surface contact area with the polymer matrix. The greatest property improvement was achieved when the nanoparticles were finely and uniformly dispersed and showed a strong affinity toward the corresponding polymer matrix [49]. The incorporation of nanofillers is often accompanied by a remarkable reinforcing effect [50]. They may work, however, also as potential flame retardants since they may be involved in the development of a thermal insulation layer on the surface of burning material during combustion. Such nanoparticles could be montmorillonite, expandable graphite, halloysite [51], bentonite, carbon nanotubes [52], and sepiolite [53].

Expandable graphite (EG) has low density, and it is non-burnable and capable of insulating the polymer substrate against radiant heat. An oxidizing acid, such as sulfuric acid or nitric acid, is intercalated within the graphite layers during the commercial EG production process. Once the graphite is exposed to heat, it will expand and form a voluminous insulation layer, providing sufficient FR to the polymeric matrix [54]. Wei et al. [55] utilized expandable graphite (EG), intercalated with sulfuric acid, to enhance the flame retardancy of PLA. They found that the burning time and dripping were suppressed when more than $5 \mathrm{wt} \%$ of EG was incorporated into PLA, yielding a V-0 rating. A slightly lower degradation temperature was observed for PLA with more than $5 \mathrm{wt} \%$ EG due to the acid-catalyzed chain scission of PLA. CCM test results showed a maximum reduction in PHRR (28\%) when $10 \mathrm{wt} \%$ EG was added into PLA. This suggested that the EG works as a FR for PLA, by reducing HRR through the generation of protective char serving as potential barrier to both mass and energy transports between the flame and the burning polymer. Bourbigot et al. [56] functionalized multiwall carbon nanotube (MWNT) with a melamine-based flame retardant (f-MWNT) to achieve high level nanoscale dispersion in the PLA matrix. A reduction of $28 \%$ in the PHRR value in PLA/f-MWNT compared to neat PLA was reported based on the mass loss calorimeter test. This was attributed to the excellent dispersion of f-MWNT in PLA. PLA/MWNT nanocomposites were prepared by Bourbigot et al. [52] by reactive extrusion. They synthesized PLA by ring opening polymerization of L,L-lactide, then mixed in the MWNT in a continuous single-stage process. They reported that the flame spread of PLA/MWNT is much lower than that of pure PLA. Mass loss calorimetry results revealed that PLA/MWNT exhibited lower HRR values than pure PLA (i.e., reduction by $20 \%$ of the PHRR compared to pure PLA). This slight improvement of flame retardancy was probably due to the formation of a char layer covering the entire sample surface, which acted as an insulation barrier and prevented volatiles from support the flaming.

Hapuarachchi and Peijs [53] utilized the unique properties of sepiolite nanoclay and MWNT to develop PLA with improved flame retardancy. The largest drop in HRC occurred when $10 \mathrm{wt} \%$ sepiolite nanoclay was used together with $2 \mathrm{wt} \%$ of MWNT. This was probably due to the MWNT bridging of the sepiolite clay stacks resulting in a tighter char during decomposition. It was justified that $10 \mathrm{wt} \%$ sepiolite is sufficient to create a protective barrier while $2 \mathrm{wt} \%$ MWNT is able to form a network within the system. It was believed that the silicate char layer serves as a protective barrier, preventing the volatiles gases escaping and oxygen ingress during fire.

PLA nanocomposites based on organomodified layered silicate (OMLS) and calcium sulphate hemihydrate (AII) - a by-product during the lactic acid manufacturing process - were prepared and evaluated by Murariu et al. [57]. During the UL-94 burning test, 
HB classification was achieved for PLA/AII/OMLS nanocomposites; with a moderate burning rate (30$33 \mathrm{~mm} / \mathrm{min}$ ), with charring and no dripping during the test. It is noteworthy that the PLA/AII composite burned with drips at a relatively low burning rate (19 $\mathrm{mm} / \mathrm{min}$ ), but no char formed on the burning specimen. While OMLS can cause a significant reduction in PHRR, the incorporation of AII delayed the TTI of PLA/AII/OMLS during CCM experiments. It was suggested that the formation of a char layer during combustion could be the reason for HRR reduction.

Stoclet et al. [51] produced PLA nanocomposites based on halloysite nanotube (HNT), using waterassisted extrusion. Water-assisted melt compounding of suitable nanofillers is a straightforward and safe method of producing nanocomposites [58]. The effect of HNT on the dispersion and fire properties of the water-assisted extruded nanocomposites (PLA$\mathrm{H}-\mathrm{W}$ ) were evaluated and compared with those of traditional melt extruded nanocomposites (PLA-H). The use of water during melt compounding had a positive effect on the dispersion of HNT, indicated by an almost fully exfoliated morphology, even for the PLA containing $17 \mathrm{wt} \%$ HNT (PLA-H17-W). The CCM test revealed that the PHRR decreased monotonously with increasing clay loadings and this effect was more pronounced for PLA-H-W than for PLA$\mathrm{H}$. The phenomenon was related to the high level nanoscale dispersion of HNT improving the FR of PLA-H-W. The formation of an inorganic-rich layer at the surface of the sample during combustion insulated the underlying substrate from the external environment, limiting the transport of mass between the condensed and gas phases.

A series of PLA nanocomposites based on graphene and ionic liquid containing phosphonium ([PCMIM] $\mathrm{PF}_{6}$, IL) surface-functionalized graphene (GIL) were prepared via melt compounding by Gui et al. [59]. The surface of graphene was functionalized with IL before being incorporated into the PLA matrix. Good fire performance was achieved with the addition of $4 \mathrm{wt} \%$ GIL, where the LOI value of PLA (19\%) increased to $28 \%$. Moreover, the formulation was rated as V-1 in the UL-94V burning test with a significant reduction in PHRR from 324 to $99 \mathrm{~kW} / \mathrm{m}^{2}$ under $\mathrm{CCM}$ test conditions. This was traced to individually dispersed GIL supporting the formation of a rigid network between graphene and IL, to an increment in the char yield, and to the development of a continuous and compact char layer. This way the matrix was protected against heat penetration and further degradation.

$\mathrm{Hu}$ et al. [60] investigated the effect of MWNT and tri(1-hydroxyethyl-3-methylimidazolium chloride phosphate) (IP) functionalized MWNT (MIP) on the flame resistance properties of PLA. The addition of $5 \mathrm{wt} \%$ MIP (PLA/5MIP) yielded an increase of the LOI value from 19 to $26 \%$. The PLA/5MIP composites reached a V-1 rating in the UL-94 test with a notable reduction in the PHRR and THR values (PHRR: $155 \mathrm{~kW} / \mathrm{m}^{2}$; THR: $34 \mathrm{~kW} / \mathrm{m}^{2}$ ) in the CCM test. In addition, the char residues for the PLA/5MIP composite were more continuous and compact than for PLA/ 5MWNT. Results suggested that IP catalyzed the carbonization of the degradation products, whereas MWNT acted as a physical crosslinking network, absorbing degradation products. The combined effect of both IP and MWNT led to the formation of more compact char, which gave a better protection of materials against heat and thermal oxidation.

Ju et al. [61] prepared flame-retarded PLA nanocomposites based on nanoattapulgite (NATP) coated with resorcinol bis(diphenyl phosphate) (RDP). They reported that PLA/RDP-NATP nanocomposites successfully achieved a $\mathrm{V}-0$ rating with an LOI value of $24.5 \%$ when $30 \mathrm{wt} \%$ of RDP-NATP was added. A reduction in melt dripping and the formation of a large amount of char was found in the presence of RDP-NATP. Scanning electron microscopy (SEM) on the residual char revealed that a dense and continuous, cortical-honeycomb structured char formed. This suggested that the migrated NATP on the burning surface was crosslinked by a large amount of char produced via the interaction between RDP and PLA.

Liu et al. [62] used double modified pristine MMT to improve the fire retardancy of PLA. First the surface of the sodium-MMT was organically modified by cetyl trimethyl ammonium bromide then by resorcinol bis(diphenyl phosphate) via ion-exchange and adsorption, respectively. The introduction of $5 \mathrm{wt} \%$ modified MMT into PLA increased the temperature linked with 5 and $50 \mathrm{wt} \%$ mass loss by 16 and $17^{\circ} \mathrm{C}$, respectively. Meanwhile, the PHRR was reduced by $34 \%$. These improvements were ascribed to the physical barrier effect of the MMT nanosheets and the charring effect of its modifier compounds. 


\subsection{Poly(lactic acid) with novel synthesized flame retardant}

Most research studies quoted that heavy loadings of additive FRs (generally 20-50 wt $\%$ ) are usually required to provide a polymer with certain flame retardancy. However, this is generally associated with a substantial deterioration in mechanical properties, processability, and other physical properties due to the thermodynamical immiscibility between PLA and the flame retardants. For this reason, halogenfree synthesized flame retardants are being introduced, aimed at improving fire the properties of polymeric materials. They can be used in low amounts, and the properties of the polymer do not change considerably.

Tao et al. [63] reported the development of flameretarded PLA based on a synthesized flame retardant, phosphazene cyclomatrix network polymer poly(cyclotriphosphazene-co-pentaerythritol) (PCPPE). They found that the addition of only $5 \mathrm{wt} \%$ PCPPE is sufficient to endow PLA with a V-0 rating in UL-94 burning test. A significant amount of residual mass remaining after the burning of PLA containing $20 \mathrm{wt} \%$ PCPPE in the CCM test (i.e., $76 \mathrm{wt} \%$ ) suggested the formation of a cohesive char layer. This acted as an insulating barrier between fire and the PLA resin and effectively retarded the combustion of the material during the ignition/burning process.

Xi et al. [64] synthesized a novel FR of high efficiency and good compatibility with PLA, which contained phosphaphenanthrene and triazine-trione groups. It was melt blended to PLA in up to $10 \mathrm{wt} \%$. The flame retardancy of the corresponding PLA composites was characterized using the LOI, UL 94 vertical burning and cone calorimeter tests. The $10 \mathrm{wt} \%$ FR-containing composite showed an LOI of $26.1 \%$ and also passed the UL $94 \mathrm{~V}-0$ rating. Through partial replacement of this FR by melamine cyanuric (with dilution effect) and hexa-phenoxy-cyclotriphosphazene (with quenching effect), the newly synthesized FR acted as both diluent and quencher.

Lin et al. [65] synthesized a new flame-retardant poly (1,2-propanediol 2-carboxyethyl phenyl phosphinate) (PCPP) using 2-carboxyethyl phenylphosphinic acid (CEPPA) and 1,2-propanediol (PD). In the UL-94 test, $\mathrm{V}-0$ classification was obtained when only $5 \mathrm{wt} \%$ PCPP was incorporated. The maximum LOI (28.2\%) value was achieved when $10 \mathrm{wt} \%$ PCPP was incorporated in the PLA. Severe melting drips were found for PLA with higher PCPP loading (7-30 wt\%). This suggested that the molten mass drip from the matrix had taken out heat generation during combustion, and led to flame extinguishment. In a follow-up paper Lin et al. [66] studied the thermal degradation behavior of the blend composed of PLA and PCPP (added in $15 \mathrm{wt} \%$ ) by TGA, TGA-FTIR and pyrolysis gas chromatography-mass spectrometry analysis. The activation energy of thermal degradation, calculated by the Flynn-Wall-Ozawa method, increased in the presence of PCPP when the degradation conversion was higher than 10\%. PCPP improved the flame-retardancy of PLA by inhibiting the exothermic oxidation reactions in the combustion. PCPP in the gas phase altered the release of flammable and nonflammable gases rather than changing the way of pyrolysis.

Zhao et al. [67] successfully improved the flammability of PLA using a low amount of flame retardant. A super-efficient flame retardant, $N, N^{\prime}$-diallyl-Pphenylphosphonicdiamide (P-AA) was developed and incorporated into the PLA matrix. They aimed to keep a balance between flame retardancy and other properties such as thermal and mechanical properties. It is worth noting that the LOI value reached $28.4 \%$ with a UL-94 V-0 rating at a thickness of $3.2 \mathrm{~mm}$ when $0.5 \mathrm{wt} \%$ P-AA was added to PLA. Furthermore, a decrease of the PHRR from $435 \mathrm{~kW} / \mathrm{m}^{2}$ (PLA) to $366 \mathrm{~kW} / \mathrm{m}^{2}$ (PLA containing 0.5 and $1 \mathrm{wt} \%$ P-AA) was observed, confirming that P-AA induced incomplete combustion. Few residues were obtained after the CCM test indicated that P-AA inhibited flame in gas phase by generating $\mathrm{PO} \cdot$ radicals at elevated temperatures, which scavenged $\mathrm{H} \cdot$ and $\mathrm{OH}$. radicals produced during polymer decomposition. Jing et al. [68] reported the two-step synthesis of a novel bio-based polyphosphonate (BPPT). BPPT was synthesized via the condensation reaction of a diphenolic acid, a 1-oxo-2,6,7-trioxa-1-phosphabicyclo $[2,2,2]$ octane-4-methanol and phenylphosphonic dichloride. The LOI value of PLA, melt blended with 2,4 and $6 \mathrm{wt} \%$ BPPT, increased from the initial $20 \%$ (PLA) to $28.8,33.7$ and $35.4 \%$, respectively. Additionally, a V-0 level according to the UL 94 flammability test was reached at a BPPT loading of $4 \mathrm{wt} \%$, which is extremely low. Such an outstanding flame retardancy of PLA/BPPT was attributed to the gas phase mechanism of BPPT in quenching the flame, which was further confirmed through $\mathrm{CCM}$ and TGA measurements.

It is known that red phosphorus (RP) is an unstable substance and generates poisonous phosphine during 
decomposition in a disproportionation reaction with moisture and oxygen. Therefore, novel double-layered microencapsulated red phosphorus (DMRP) was prepared by Chang et al. [69] through chemical precipitation of aluminum trihydrate (ATH) and in situ polymerization of melamine formaldehyde (MF) resin on the RP powder surface. The flammability of PLA containing DMRP (PLA-DMRP) and conventional microencapsulated RP (PLA-CMRP) was compared. It was demonstrated that PLA-DMRP has superior flame resistance to PLA-CMRP, while heavy flammable melt dripping was observed for PLACMRP (UL-94 V-2). By contrast, no dripping occurred in PLA-DMRP (UL-94 V-0). It was hypothesized that the improvement of flame retardancy was related to nitrogen-phosphorus synergism and the endothermic decomposition of the MF resin, which generates water and nitrogen compounds, diluting the flammable oxygen and combustion fuel. Besides, the encapsulated ATH decreased the gas generated by RP during burning due to the smoke suppression effect of ATH.

\subsection{Chemical modification of poly(lactic acid) chain}

To improve the poor flame retardancy of PLA, its polymer chain became the target of modifications strategies. Wang et al. [70] developed a novel approach to prepare flame-retarded PLA. They used a reactive flame retardant, ethyl phosphorodichloridate, as a chain extender to synthesize phosphorous-containing PLA (PPLA) in the backbone. MCC experiments revealed that the shape of the HRR curve of PPLA became broader and shifted to lower values compared with the sharp curve of PLA. This indicated that the decomposition process of PPLA was changed by the incorporation of phosphorus into the backbone of PLA. At the same time, PPLA had good flame retardant properties (V-0 in the UL-94 test with an LOI value of $25 \%$ ) even when only $5 \mathrm{wt} \%$ PPLA was added into PLA.

Yuan et al. [71] chemically coupled an effective organophosphorus-based FR, hydroquinone derivative of DOPO (HQ-DOPO), into the PLA backbone (IFR-PLA) via chain extension dihydroxyl-terminated telechelic PLA (HO-PLA-OH) with 1,6-hexamethylene diisocyanate (HDI). IFR-PLA with various phosphorus contents and $[\mathrm{NCO}] /[\mathrm{OH}]$ feeding ratios were prepared. It was reported that all IFR-PLAs with phosphorus content of $1-2 \%$ had LOI values of
$29-33 \%$ and a V-0 rating according to the UL-94 test. Interestingly, the addition of $30 \mathrm{wt} \%$ IFR-PLA (1\% phosphorus) into PLA yielded an UL-94 V-0 rating with an LOI of $25 \%$.

\subsection{Poly(lactic acid) with hybrid flame retardant}

The development of hybrid materials as flame retardants has drawn significant attention in recent years. They are produced from a combination of organic and inorganic components through chemistry processes, including sol-gel [72], intercalation, exchange, or grafting methods [73]. The existence of an organic unit in the hybrid structure is essential to enhance compatibility with the polymer matrix, whereas the inorganic part of the hybrid additive is responsible for the FR properties of the host polymer.

Cao et al. [73] synthesized a novel nanorod-shaped hybrid flame retardant (NRH-FR) through the reaction of benzenephosphinic acid (BPA) with aluminum hydroxide (ATH) powder. With the addition of $30 \mathrm{wt} \%$ NRH-FR, the nanocomposite successfully reached the V-0 rating in the UL-94 test and an LOI value of $25.0 \%$ without dripping. SEM results found that a coherent and tight char layer formed on the burning surface of the specimens. It was predicted that BPA units in NRH-FR released $\mathrm{PO}_{2}$. radicals, which can inactivate free radicals in the vapor phase, whereas ATH in NRH-FR released water vapor during burning, lowering the temperature of the condensed phase and diluting the concentration of combustible gases in the vapor phase.

Qian et al. [74] reduced the flammability of PLA by adding aluminated mesoporous silica (Al-SBA-15) which was produced by post-grafting aluminum isopropoxide on the surface of mesoporous silica (SBA15). It was found that PLA containing $0.5 \mathrm{wt} \% \mathrm{Al}$ SBA-15 was able to increase the LOI of the composite to $30 \%$, which reached a V-0 classification in the UL-94V burning test. Little inflammable dripping was observed during the burning test. Therefore, the heat was dissipated to the environment through harmless dripping, thereby improving the flame retardancy of PLA. Besides, volatile gas released by PLA during degradation was greatly reduced in the presence of Al-SBA-15, which was attributed to the adsorption and retardation of released volatile gas via the labyrinth effect. The latter was often quoted as the major contributing factor of the improved thermal resistance of polymeric nanocomposites [75]. 


\subsection{Poly(lactic acid) composites with combination of flame retardants}

Several possible flame retardancy effects, including additive, synergism or antagonism, can be produced through the interplay between two or more flame retardants. The sum of the individual actions is regarded as additive, while the effect beyond the rule of additivity would be considered as 'synergistic'. Antagonism will occur when the combination of flame retardants results in poorer performance than the sum of the FR additives individually. Synergism among flame retardants is very important since it allows the reduction of the amount of FRs without jeopardizing structural properties and processability.

In order to improve the flame retardant properties of PLA, Zhu et al. [76] introduced APP and EG into PLA via melt blending. A synergistic flame retarding effect between APP and EG was observed for PLA in both the UL 94 and LOI tests. The incorporation of $15 \mathrm{wt} \%$ APP and EG (APP/EG in 1/3) gave an LOI value of $36.5 \%$ and an UL $94 \mathrm{~V}-0$ rating. In addition, a significant reduction in PHRR, THR and mass loss rate was observed for PLA/APP/EG in CCM analysis. Such improvement in flame retardancy was related to the formation of a continuous, dense and sealed char layer during combustion as a consequence of filling the EG flakes by the viscous degradation products of PLA/APP. This layer separated the matrix from heat and oxygen effectively and inhibited the further degradation of the PLA.

Tang et al. [54] investigated a series of flame retarding PLA composites involving aluminum hypophosphite (AHP) and EG. They reported that an optimum result was achieved when $10 \mathrm{wt} \%$ of each AHP and EG were added into PLA. This combination resulted in a UL $94 \mathrm{~V}-0$ rating along with an LOI value of $34 \%$. The CCM test displayed a significant reduction in the PHRR and THR when $15 \mathrm{wt} \%$ AHP and $5 \mathrm{wt} \%$ EG were added to the PLA. TGA-IR results revealed that the combination of these two additives reduced the decomposed gaseous products more than either AHP or EG alone when incorporated in the same overall amounts. This can be attributed to the formation of a compact inorganic layer by AHP and it can inhibit the release of gaseous products, while EG can expand and form a vermicular structure prohibiting the transportation of oxygen and fuel.

Gong et al. [77] demonstrated a synergistic flame retardancy of fumed silica $\left(\mathrm{SiO}_{2}\right)$ and nickel catalyst
$\left(\mathrm{Ni}_{2} \mathrm{O}_{3}\right)$ in PLA. The highest LOI value $(26.0 \%)$ was achieved when PLA contained $5 \mathrm{wt} \%$ of both $\mathrm{SiO}_{2}$ and $\mathrm{Ni}_{2} \mathrm{O}_{3}(\mathrm{PLA} / 5 \mathrm{Si} / 5 \mathrm{Ni})$. The PHRR of PLA/5Si/ $5 \mathrm{Ni}$ was reduced to $249 \mathrm{~kW} / \mathrm{m}^{2}$ during the CCM test. Field emission scanning electron microscopy (FESEM) and transmission electron microscopic (TEM) tests showed that a large amount of char was formed. It consisted of block-like carbon and filamentous carbon. Carbon nanotubes and carbon nanofibers were in situ formed via the catalytic carbonization of the PLA degradation products in the presence of fumed silica and nickel catalyst. It was suggested that the co-addition of $\mathrm{SiO}_{2}$ and $\mathrm{Ni}_{2} \mathrm{O}_{3}$ supported the formation of a network structure in PLA thereby increasing its melt viscosity which promoted char formation. Concurrently, $\mathrm{Ni}_{2} \mathrm{O}_{3}$ catalyzed the carbonization of PLA into char, causing a synergism in the flame retardancy of PLA.

Kiuchi et al. [78] enhanced the flame retardancy of PLA via the dual use of ATH and phenolic resin. Better fire performance (UL $94 \mathrm{~V}-1$ ) was observed for the PLA composite containing both ATH and phenol novolac (PN) resin. This was due to the high dispersibility of ATH in the PLA matrix and the formation of a large amount of char, which uniformly covered the ignited surface of the PLA composite. However, the crystallization of PLA was retarded by the $\mathrm{PN}$ resin. Thus, a high molecular-weight $\mathrm{PN}$ resin was used together with ATH, an organic nucleation agent, and polytetrafluoroethylene (PTFE) to improve the fire performance of PLA(UL $94 \mathrm{~V}-0$ ), while maintaining the high crystallization speed of PLA.

Mu et al. [79] prepared PLA with poly(bis(phenoxy) phosphazene) (SPB-100) and expandable graphite (EG) through melt compounding to enhance flame retardancy. A synergistic effect was reported for SPB100 with EG (i.e., UL94 V-0 rating, an LOI value of $34.5 \%$, and no dripping) at a total loading of $15 \mathrm{wt} \%$ FRs when the mass ratio of SPB-100/EG was 1/1. A significant reduction in PHRR (from 410 to $196 \mathrm{~kW} / \mathrm{m}^{2}$ ) was observed when both EG and SPB100 were added into the PLA matrix. Phosphorus compounds were detected on the charring surface through Fourier transform infrared spectroscopic (FTIR) and X-ray photoelectron spectroscopy (XPS) tests. Thermogravimetry-mass spectrometry (TGAMS) and TGA-IR results further confirmed that SPB-100 acted in both the condensed and the gas phases. A synergistic interaction occurred between 
SPB-100 and EG due to the formation of an intumescent char layer by EG and the gas flame retardant action of SPB-100.

Zhou et al. [80] investigated the effect of aluminum hypophosphite (AHP) and IFR on the flammability of PLA. The cited authors found that PLA containing a total amount of $10 \mathrm{wt} \%$ of IFR and AHP (weight ratio 7/3) showed improved dripping behavior (no dripping occurred during first flame application) and the PLA composite achieved a UL 94 V-0 rating along with an LOI value of $30.2 \%$. Furthermore, the CCM test revealed that the co-addition of IFR and AHP in PLA caused a significant reduction in the PHRR and THR compared to the incorporation of either AHP or IFR alone. This confirms a synergistic effect between IFR and AHP on charring, via which a strong and compact char layer is formed, imparting better flame resistance properties to PLA/IFR/AHP.

Costes et al. [81] evaluated effects of combinations of microcrystalline cellulose or nanocrystalline cellulose with a phosphorus-based flame retardant, aluminum phytate (Al-Phyt), on the flame retardancy of PLA. Cellulose was coated with phosphorous by chemical grafting and co-additive melt blending with the use of Al-Phyt. It is noteworthy that the combined use of microcrystalline cellulose and Al-Phyt did not affect the PHRR of PLA, while the co-addition of nanocrystalline cellulose and Al-Phyt significantly reduced the PHRR value. This could be assigned to the nanoscale dimension of nanocrystalline cellulose with a high specific surface area, which promotes charring through the interfacial interaction between cellulose and Al-Phyt. Higher flame retardancy was achieved when Al-Phyt was added with phosphorylated microcrystalline cellulose in PLA. The corresponding composite exhibited low PHRR and a V-2 classification in the UL 94 test suggesting that the presence of aluminum and fillers containing a high amount of phosphorus support the fast formation of a charred layer.

Attempts were also made to explore the catalytic effects of metallic compounds on the formation of char in combination with traditional FRs. Zhou et al. [82] prepared $\mathrm{ZnO}$-coated kenaf and blended it together with resorcinol di(phenyl phosphate) (RDP) to PLA. During the preparation of composites, $\mathrm{ZnO}$ was coated on the kenaf in order to provide good dispersion and catalysis effects for char formation during the combustion of PLA. The kenaf acts as the reinforcing fiber, as well as a charring source during the pyrolysis of the composites. Dense and compact char residues were found on the PLA composites containing $\mathrm{ZnO}-$ coated kenaf after combustion. All the composites containing a total of $15 \mathrm{wt} \%$ additives (i.e., RDP and $\mathrm{ZnO}$ coated-kenaf) passed the UL $94 \mathrm{~V}-0$ rating and had LOI above $27 \%$.

Although the use of nanoscale fillers has been proven to show positive potential toward flame retardancy (e.g., delayed TTI, reduction of PHRR, HRR, and mass loss rate) through developing a carbonized inorganic protective surface layer during combustion [83-85], they are still insufficient to make the polymer self-extinguishable and meet fire safety regulatory requirements. Thus, these nanofillers have to be used in conjunction with conventional flame retardants to achieve optimum fire safety performance. By the use of two or more FR additives, combination advantages could be obtained when each component participates in different, non-competing flame retardant modes (e.g., condensed phase charring together with vapor phase flame inhibition [86]).

Cheng et al. [87] prepared biodegradable PLA nanocomposites with ATH and organo-modified montmorillonite (Cloisite 30B, C30B) via direct meltcompounding using a twin-screw microextruder. The highest UL $94 \mathrm{~V}-0$ rating and LOI value were achieved when $45 \mathrm{wt} \%$ ATH and $5 \mathrm{wt} \%$ C30B were combined. This composition showed a remarkable reduction in PHRR (at approximate 65\%) in the $\mathrm{CCM}$ test. This indicates that $\mathrm{C} 30 \mathrm{~B}$ with ATH are capable of producing a solid insulation barrier during combustion, thereby improving the flame resistance properties of PLA.

Bocz et al. [88] manufactured flame retarded PLAbased self-reinforced composites (PLA-SRC) using melamine resin that encapsulated APP and MMT in a ratio of 10/1 in the matrix. Note that self-reinforced polymer composites are composed of the same polymer or of polymers belonging to the same family. A usually oriented, highly crystalline polymer in a suitable form (fiber, tape or related assemblies) works as reinforcement, whereas its amorphous or less crystalline version takes the role of matrix in these selfreinforced or single-polymer composites [89]. The above dual flame retardant was introduced in the amorphous PLA matrix in 10 and $16 \mathrm{wt} \%$. The LOI values measured for the self-reinforced PLA composites without and with 10 , and $16 \mathrm{wt} \%$ FR were 23,30 and $34 \%$. The related UL 94 ranking was HB (flame spreading: $43.5 \mathrm{~mm} / \mathrm{min}$ ), V-2 and V-0, 
respectively [88]. Mass loss type cone calorimetry results clearly demonstrated the efficiency of the combined use of APP/MMT, as shown in Figure 2. Note that the PHRR and THR values were reduced by 60 and $40 \%$, respectively, owing to the incorporation of $16 \mathrm{wt} \% \mathrm{FR}$. Another works from Bozc et al. [90] demonstrated that the flame resistance of PLA biocomposites can be improved by the using of glycerol phosphate, phosphorus silane surface treatment agent together with ammonium polyphosphate.

In our previous study [91], PLA was melt blended with organo-montmorillonite (OMMT) and isopropylated triaryl phosphate ester FR to prepare flame-retarded PLA nanocomposites with improved impact strength. It was found that PLA/OMMT/FR nanocomposites with the addition of 20 and $30 \mathrm{phr}$ of FR fulfilled the V-0 ranking according to UL 94. From the FESEM evaluation, $20 \mathrm{phr}$ was the minimum amount of FR needed to receive a good quality char in PLA/OMMT nanocomposites during combustion (c.f. Figure 3). It was believed that the decomposed FR had yielded phosphorous acids in the condensed phase, esterifying and dehydrating the polymer matrix to form char. Hence, the heat and mass transfer to the underlying polymer were inhibited and the decomposition rate of the polymer was slowed down.

Fontaine and Bourbigot [92] developed low flammability PLA with acceptable loading of IFR (up to $30 \mathrm{wt} \%$ ) in the presence of C30B and MWNT. The combined use of MA and APP in a weight ratio of $1 / 5$ yielded a synergistic effect on the flame retardancy

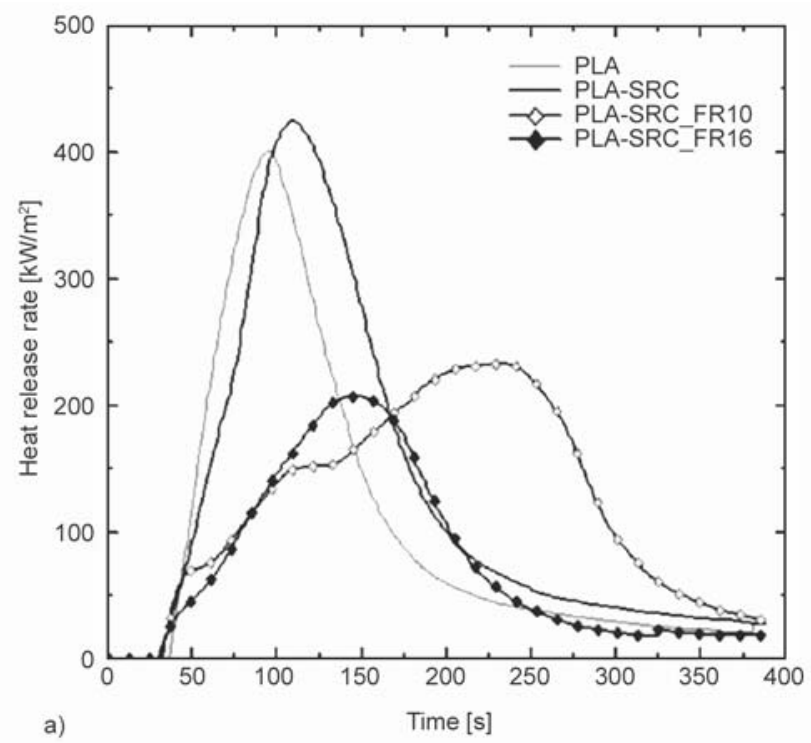

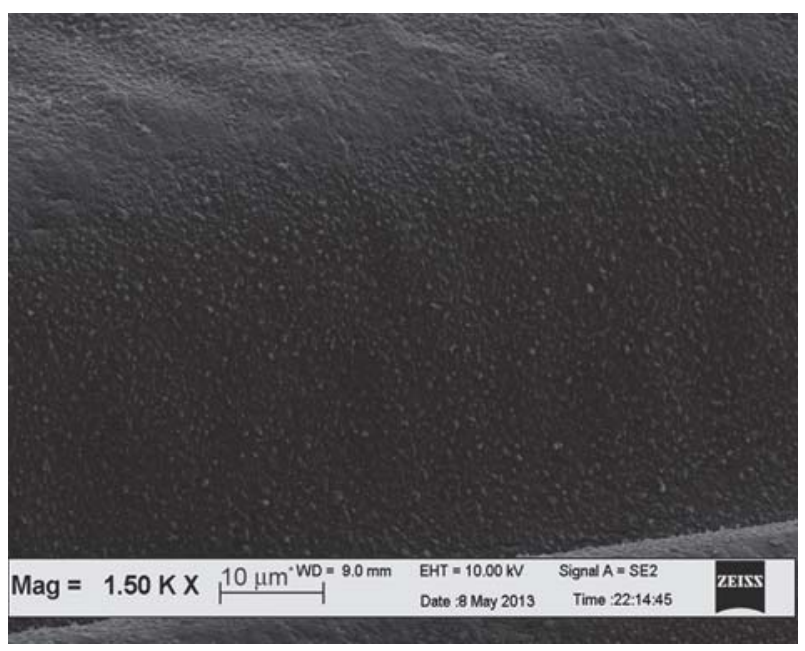

Figure 3. FESEM micrograph taken from PLA/OMMT/ FR30 after UL 94 vertical burning test.

of PLA, with high LOI values (46\%) and a V-0 classification in LOI and UL 94 tests, respectively. However, the presence of MWNT always gave an antagonistic effect, by decreasing LOI and UL 94 test results. This might be assigned to the accumulation of MWNT in the intumescent char, reaching the percolation threshold. This phenomenon will lead to an increase in thermal conductivity, affecting the efficiency of intumescent coating as a heat barrier. On the contrary, $\mathrm{C} 30 \mathrm{~B}$ acted as an effective synergist in the intumescent coating enhancing the efficiency of APP/MA [34].

Li et al. [93] improved the flame resistant properties and melt stability of PLA using IFR (based on ammonium polyphosphate, melamine and pentaerythritol)

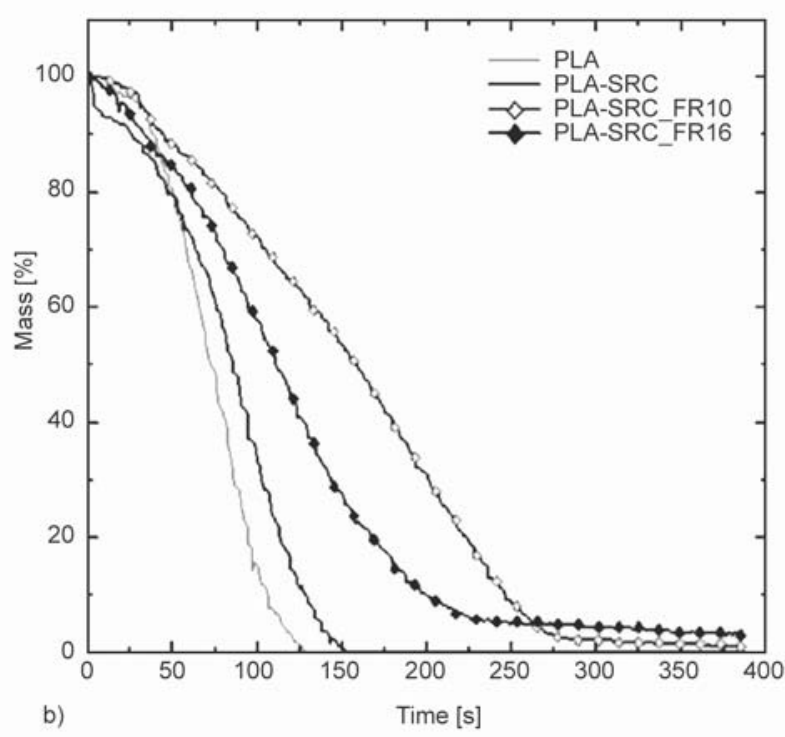

Figure 2. Cone calorimetry results showing the HRR (a) and mass loss (b) as a function of burning time. Designations: SRCself-reinforced composite with a nominal reinforcement content of ca. $50 \mathrm{wt} \%$, FR-total amount of APP/MMT added in 10/1 ratio (Courtesy of Dr. K. Bocz, BME, Budapest, Hungary, August, 2016). 
and OMMT. It was demonstrated that PLA containing $15 \mathrm{wt} \%$ IFR and $5 \mathrm{wt} \%$ OMMT successfully fulfilled the V-0 ranking in the UL 94 test and had an LOI value of $27.5 \%$. Surprisingly, no melt dripping was observed in PLA/IFR/OMMT, possibly due to the anti-dripping effect of OMMT. It is noteworthy that the interplay between the action of IFR and an appropriate melt viscosity is required to support the formation of a continuous, dense char layer with suitable strength (cracking resistance) irrespective of its porous structure.

Wang et al. [94] successfully improved the flammability of PLA with IFR (containing APP, PER and melamine cyanurate (MC) in weight ratios 2:2:1) and organomodified zinc aluminum layered double hydroxide (ZnAl-LDH). CCM experiments revealed that the THR of neat PLA was markedly reduced from 152 to $35 \mathrm{MJ} / \mathrm{m}^{2}$ for the PLA/IFR/ZnAl-LDH system. Lower mass loss rate and higher char yield found for the PLA/IFR/ZnAl-LDH nanocomposite than neat PLA and PLA/IFR indicated the PLA was not completely burnt due to the formation of intumescent char on the surface of the matrix, acting as a thermal insulator resulting in flame extinguishment.

Flame retarded PLA systems based on pentaerythritol phosphate (PEPA), melamine phosphate (MP), and trisilanolisbutyl-polyhedral oligomeric silsesquioxanes (TPOSS) were prepared by Song et al. [95]. PEPA was synthesized and mixed with MP as IFR for PLA before melt-blending with PLA and TPOSS. With the addition of $20 \mathrm{wt} \%$ IFR (i.e., combination of PEPA and MP) and $5 \mathrm{wt} \%$ TPOSS, the LOI value reached $36.0 \%$ along with an UL $94 \mathrm{~V}-0$ rating. The enhancement in flame retardancy was related to the synergistic interaction between TPOSS and IFR, yielding an intumescent high quality char that protected the PLA from further degradation. Phosphorus from IFR was responsible for char development whereas the silica from TPOSS protected the char against thermal degradation.

Serious dripping behavior of PLA during pyrolysis remained an urgent task to be solved since these melting drips are able to ignite other materials and propagate fire. Zhan et al. [96] found effective antidripping agents for PLA containing intumescent flame retardants. OMMT, zinc borate, fumed silica, tetraethoxysilane (TEOS) and PTFE were added as antidripping synergists for PLA/IFR. It was reported that $15 \mathrm{wt} \%$ OMMT and zinc borate produce the best anti-dripping effect (without melting drips) while maintaining its excellent flame retardancy properties (an UL 94 V-0 rating) when used with IFR. During the combustion process of PLA/IFR/OMMT, a compact char barrier layer, containing more silicate stacks was formed, which prevented dripping. In the PLA/ IFR/zinc borate composite, the zinc borate tends to participate in the formation of a vitreous continuous layer, which is accompanied by an increase of the viscosity of the system. This layer provided a protective barrier against heat and oxygen, and suppressed the dripping phenomenon during the burning test.

\section{Analysis of current development 3.1. Analysis based on flammability tests}

The flame retardancy of a polymeric material is well correlated with its intrinsic properties, such as molecular structure and chemical composition. Therefore, flame resistance properties can be improved either through chemical modification of the polymer structure or by the addition of flame retardants (alone or in combination with other additives) into the polymer matrix. Recent developments in flame retarded PLA underline that prominent improvements can be achieved through the incorporation of flame retardant additives into the PLA. The additives are mainly composed of halogen-free phosphorus compounds, micro- and nanoparticles, and intumescent flame retardants that are eco-friendly and can be recycled. Due to the limitation of currently available flame retardants for PLA, some of them are synthesized or modified before applied to PLA.

Figure 4 shows the UL 94-LOI matrix that summarizes the flame retardants used in PLA and its composites with their respective performance under the UL 94 vertical burning and limiting oxygen index (LOI) test (c.f. indicator remarks in Table 3). One can notice that conventional FRs yield flame-retarded PLAs with either V-2 or V-0 rating according to the UL 94 vertical burning test, depending on the amount of the added flame retardants. Higher loadings of FR (i.e., 20-40 wt \%) are required to impart better flame retardancy (i.e. self-extinguishable, smoke suppression, improved dripping behavior) in PLA. Most conventional FRs play their role in a condensed phase: they promote char formation and/or enhance melt flow to quench flame propagation. The LOI values of PLA/conventional flame retardants fall in the range of $25-30 \%$, when the formulations meet the UL 94 $\mathrm{V}-0$ rating. 


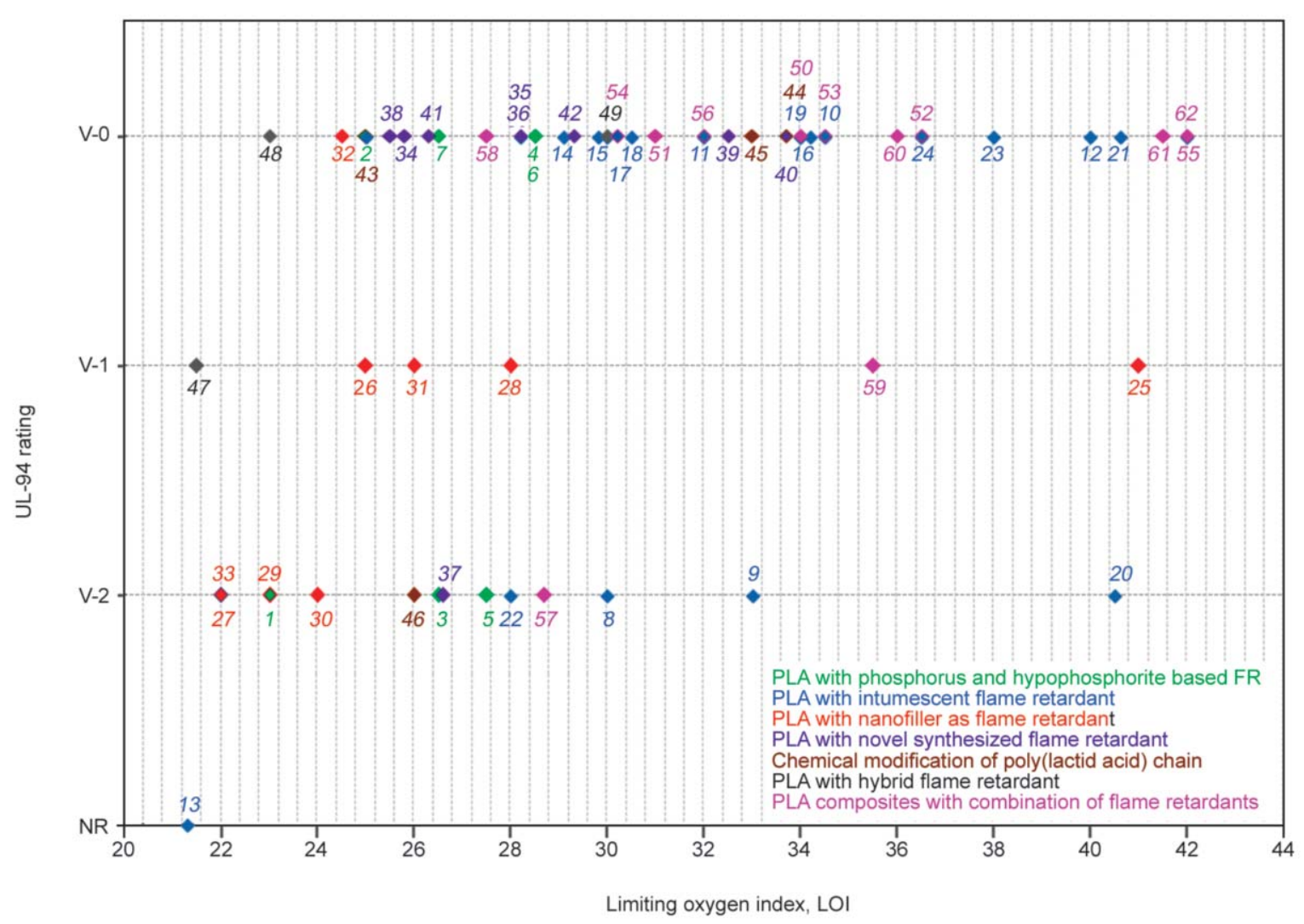

Figure 4. Summary of flame retardants used in PLA and its composites and their performance in the UL 94 vertical burning test and limiting oxygen index (LOI) test (Note: The numbers in italics indicate the remarks for each flame retardant).

Similarly to conventional flame retardants, intumescent flame retardants (IFR) also have to be applied in high amounts $(20-40 \mathrm{wt} \%)$ to imbue PLA with significant flame resistance properties. Through the interaction between the acid source, carbonization agent, and blowing agent, IFR systems work effectively in the condensed phase by forming an intumescent char layer. IFR-induced char morphology offers better flame resistance to PLA compared to char layers formed by conventional FRs. Thus, PLA/ IFRs exhibit better LOI performance (i.e., 29-41\%) than PLA/conventional FRs when they reach UL 94 V-0 classification.

PLA/synthesized flame retardants were prepared either through: (i) chain modification of the PLA to trigger inherent flame retardancy or (ii) synthesizing flame retardants, then blending them into PLA. PLA/synthesized flame retardants with only $0.3-20 \mathrm{wt} \%$ of the additives may exhibit a V-0 rating in the UL 94 vertical burning test along with LOI values of $25-34 \%$. Such a high efficiency was assigned to the existence of a vapor phase mechanism in conjunction with a condensed phase mechanism in fire extinguishing. In order to improve the interfacial adhesion between PLA and fillers and to prevent the hydrolysis of certain flame retardants (e.g., red phosphorus, ammonium polyphosphate), FR compounds should be modified prior to being applied in PLA. It is worth noting that these modified flame retardants, incorporated in relatively low amounts (i.e., 4-30 wt\%), are able to render PLA with an UL $94 \mathrm{~V}-1$ or UL $94 \mathrm{~V}-0$ rating. However, their efficiency in the LOI test (at around $24-30 \%$ ) is not as good as IFR, synthesized FR, and the combined use of FRs. These modified flame retardants function mainly in the condensed phase by producing a stable char layer, thereby suppressing the combustion of the polymer substrate.

The combination of FRs is a promising route to achieve significant improvements in the flame retardancy of polymers. Note that the combination of additives in moderate amounts (i.e., $10-30 \mathrm{wt} \%$ ) is necessary for PLA to gain UL $94 \mathrm{~V}-0$ ranking of flame retardancy. Interestingly, these combinations can provide flame-retarded PLA with excellent LOI performance (i.e., LOI values between $27-42 \%$ ). This is due to the development of protecting barrier layers given by carbonaceous or intumescent char layers, which are reinforced by micro- or nanoscale fillers (synergists). Because of the excellent performance provided by the combined use of FRs in the UL 94 vertical 
Table 3. Indicator remarks for Figure 4.

\begin{tabular}{|c|c|c|}
\hline $\begin{array}{c}\text { Italic } \\
\text { number in } \\
\text { Figure } 4\end{array}$ & Materials code and composition & Ref. \\
\hline 1 & PLA/WLA-3 (100/3) & {$[35]$} \\
\hline 2 & PLA/WLA-3 (100/7) & [35] \\
\hline 3 & PLA/LaHP (80/20) & [36] \\
\hline 4 & PLA/LaHP (70/30) & {$[36]$} \\
\hline 5 & PLA/CeHP (80/20) & [36] \\
\hline 6 & PLA/CeHP (70/30) & [36] \\
\hline 7 & $\mathrm{PLA} / \mathrm{CaHP}(70 / 30)$ & [37] \\
\hline 8 & PLA/APP (77/23) & [40] \\
\hline 9 & PLA/APP/LIG (77/18.4/4.6) & [40] \\
\hline 10 & PLA/APP/UM-Lig (77/18.4/4.6) & [40] \\
\hline 11 & PLA/APP/LIG (60/30/10) & [41] \\
\hline 12 & PLA/APP/ST (60/30/10) & [41] \\
\hline 13 & PLA/CD (80/20) & {$[42]$} \\
\hline 14 & PLA/APP/CD (80/10/10) & {$[42]$} \\
\hline 15 & PLA/MA/CD (80/10/10) & {$[42]$} \\
\hline 16 & PLA/APP/MA/CD (80/5/10/5) & {$[42]$} \\
\hline 17 & PLA/APP/MA/CD (80/10/5/5) & [43] \\
\hline 18 & PLA/APP/MA/PPG/CD (80/10/5/0.75/4.25) & {$[43]$} \\
\hline 19 & PLA/APP/MA/PPR (80/10/5/5) & [43] \\
\hline 20 & PLA/APP/TT23 (70/25/5) & [46] \\
\hline 21 & PLA/APP/TT4 (70/25/5) & {$[46]$} \\
\hline 22 & PLA/SPDPM (95/5) & {$[47]$} \\
\hline 23 & PLA/SPDPM $(75 / 25)$ & [47] \\
\hline 24 & PLA/IFR (70/30); IFR = APP/HPCA & [48] \\
\hline 25 & PLA/EG (80/20) & {$[54]$} \\
\hline 26 & PLA/IL (97/3) & [59] \\
\hline 27 & PLA/Gra (99/1) & [59] \\
\hline 28 & PLA/GIL (Gra/IL) (96/4) & [59] \\
\hline 29 & PLA/MWNT (95/5) & {$[60]$} \\
\hline 30 & PLA/IP (95/5) & {$[60]$} \\
\hline 31 & PLA/MIP (95/5); MIP = MWNT/IP & {$[60]$} \\
\hline
\end{tabular}

burning test and the LOI test, they are promising candidates for the practical use in PLA products.

For the future it can be predicted that highly efficient flame retardant formulations will be developed which are needed in low amounts to render PLA with the required flame resistance without sacrificing its other properties. The related research will mostly cover chemical synthesis, surface modification and a combined use of additives.

\subsection{Analysis based on combustion tests}

Table 4 represents the summary of FRs which are used in PLA and their respective performance in the CCM test. Since most CCM tests are performed at a heat flux of $35 \mathrm{~kW} / \mathrm{m}^{2}$ and a sample thickness of $3 \mathrm{~mm}$, the following analysis is fairly appropriate.

\begin{tabular}{|c|c|c|}
\hline $\begin{array}{c}\text { Italic } \\
\text { number in } \\
\text { Figure } 4\end{array}$ & Materials code and composition & Ref. \\
\hline 32 & PLA/RDP-NATP (70/30) & [61] \\
\hline 33 & PLA/RDP-NATP (90/10) & [61] \\
\hline 34 & PLA/PCPPE (90/10) & [63] \\
\hline 35 & PLA/PCPPE $(80 / 20)$ & [63] \\
\hline 36 & PLA/PCPP (90/10) & [65] \\
\hline 37 & PLA/PCPP (97/3) & [65] \\
\hline 38 & PLA/P-AA $(99.7 / 0.3)$ & [67] \\
\hline 39 & PLA/P-AA (99/1) & [67] \\
\hline 40 & PLA/BPPT (96/4) & [68] \\
\hline 41 & PLA/CMRP (75/25) & [69] \\
\hline 42 & PLA/DMRP (75/25) & [69] \\
\hline 43 & PLA/PPLA (95/5) & [70] \\
\hline 44 & PLA/PPLA (90/10) & [70] \\
\hline 45 & IFR-PLA $[\mathrm{NCO}] /[\mathrm{OH}]=1.05: 1$ & [71] \\
\hline 46 & PLA/IFR-PLA (80/20) & [71] \\
\hline 47 & PLA/NRH-FR (90/10) & [73] \\
\hline 48 & PLA/NRH-FR (80/20) & [73] \\
\hline 49 & PLA/Al-SBA-15 (99.5/0.5) & [74] \\
\hline 50 & PLA/AHP/EG (80/10/10) & [54] \\
\hline 51 & PLA/AHP/EG $(80 / 15 / 5)$ & [54] \\
\hline 52 & PLA/APP/EG (85/3.75/11.25) & [76] \\
\hline 53 & PLA/SPB-100/EG (85/7.5/7.5) & [79] \\
\hline 54 & PLA/AHP/IFR (90/7/3) & {$[80]$} \\
\hline 55 & PLA/ATH/C30B (50/45/5) & [87] \\
\hline 56 & PLA/APP/MA/MWNT (70/24.17/4.83/1) & [92] \\
\hline 57 & PLA/IFR (80/20); IFR = APP/MA/PER & [93] \\
\hline 58 & PLA/IFR/OMMT (80/15/5) & [93] \\
\hline 59 & PLA/IFR/TPOSS (75/23/2) & [95] \\
\hline 60 & PLA/IFR/TPOSS (75/20/5) & [95] \\
\hline 61 & PLA/IFR/OMMT (80/19/1); IFR = APP/MA & [96] \\
\hline 62 & PLA/IFR/ZB (80/18/2) & [96] \\
\hline
\end{tabular}

The majority of the FRs listed in this table exhibit their actions in the condensed phase. It can be clearly observed that the FRs which mainly function in the vapor phase give lower reduction in the PHRR (i.e., 4-16\%) and THR (i.e., 6-9\%) than those acting in the condensed phase (through enhanced char formation [97]). Surprisingly, these flame retardants are able to imbue PLA with delayed TTI.

Nanoscale synergists contribute to flame retardancy mechanism through the formation of a silicate protective layer yielding PLA nanocomposites with moderate drop in PHRR (i.e., 15-45\%). In certain formulations, for example HNT, shorter TTI was noticed for the nanocomposites. This can be attributed to an earlier degradation of PLA in the corresponding nanocomposite, due to the existence of Brönsted acid 
Table 4. Summary of flame retardants used in PLA and its composites with their performance under cone calorimetry (CCM) analysis.

\begin{tabular}{|c|c|c|c|c|c|c|c|}
\hline \multirow[b]{2}{*}{$\begin{array}{l}\text { Material designations and } \\
\text { composition }\end{array}$} & \multicolumn{5}{|c|}{ Combustion properties } & \multirow[b]{2}{*}{ Explanations } & \multirow[b]{2}{*}{ Ref. } \\
\hline & $\begin{array}{l}\text { Heat flux } \\
{\left[\mathrm{kW} / \mathrm{m}^{2}\right]}\end{array}$ & $\begin{array}{l}\text { Thickness } \\
\text { [mm] }\end{array}$ & $\begin{array}{c}\text { PHRR } \\
{\left[\mathrm{kW} / \mathrm{m}^{2}\right]} \\
(\% \text { of change })\end{array}$ & $\begin{array}{c}\text { THR } \\
{\left[\mathrm{MJ} / \mathrm{m}^{2}\right]} \\
(\% \text { of change })\end{array}$ & $\begin{array}{c}\text { TTI } \\
\text { [s] } \\
\text { (\% of change) }\end{array}$ & & \\
\hline PLA/WLA-3 (100/7) & 35 & 3 & $407(-4.68)$ & $145(-0.68)$ & $87(+11.54)$ & $\begin{array}{l}\text { Induce dripping } \\
\text { with gas phase } \\
\text { mechanism }\end{array}$ & {$[35]$} \\
\hline $\begin{array}{l}\text { PLA/AII }(57 / 43) \\
\text { PLA/AII/B104 (57/40/3) } \\
\text { PLA/AII/C30B (57/40/3) }\end{array}$ & $\begin{array}{l}35 \\
35 \\
35 \\
\end{array}$ & $\begin{array}{l}3 \\
3 \\
3\end{array}$ & $\begin{array}{l}319(-14.7) \\
230(-38.5) \\
217(-41.98) \\
\end{array}$ & $\begin{array}{l}\text { N/A } \\
\text { N/A } \\
\text { N/A }\end{array}$ & $\begin{array}{l}98(+30.67) \\
88(+17.33) \\
91(+21.33) \\
\end{array}$ & \begin{tabular}{|l|} 
Formation of \\
silicate rich \\
char layer
\end{tabular} & {$[57]$} \\
\hline $\begin{array}{l}\text { PLA/SPB-100 }(85 / 15) \\
\text { PLA/EG }(85 / 15) \\
\text { PLA/SPB-100/EG }(85 / 7.5 / 7.5)\end{array}$ & $\begin{array}{l}35 \\
35 \\
35\end{array}$ & $\begin{array}{l}3 \\
3 \\
3\end{array}$ & $\begin{array}{l}402(-1.95) \\
139(-66.1) \\
196(-52.2)\end{array}$ & $\begin{array}{l}25.7(-5.51) \\
19.8(-27.2) \\
22.6(-16.91)\end{array}$ & $\begin{array}{l}58(+383.33) \\
40(+233.33) \\
32(+166.67)\end{array}$ & $\begin{array}{l}\text { Formation of } \\
\text { intumescent } \\
\text { char layer and } \\
\text { gas phase } \\
\text { mechanism }\end{array}$ & [79] \\
\hline $\begin{array}{l}\text { PLA/PCPP }(90 / 10) \\
\text { PLA/PCPP }(80 / 20)\end{array}$ & $\begin{array}{l}35 \\
35\end{array}$ & $\begin{array}{l}3 \\
3\end{array}$ & $\begin{array}{l}229.74(-15.52) \\
122.55(-54.94)\end{array}$ & $\begin{array}{r}57(-12.44) \\
14.8(-77.27)\end{array}$ & $\begin{array}{l}54(-10) \\
47(-21.67)\end{array}$ & $\begin{array}{l}\text { Formation of } \\
\text { stable and } \\
\text { compact char } \\
\text { layer }\end{array}$ & [63] \\
\hline $\begin{array}{l}\text { PLA/LaHP (70/30) } \\
\text { PLA/CeHP (70/30) }\end{array}$ & $\begin{array}{l}35 \\
35\end{array}$ & $\begin{array}{l}3 \\
3\end{array}$ & $\begin{array}{l}286(-47.91) \\
296(-46.08)\end{array}$ & $\begin{array}{l}64.3(+3.21) \\
67.7(+8.67)\end{array}$ & $\begin{array}{l}42(-26.32) \\
44(-22.81)\end{array}$ & $\begin{array}{l}\text { Formation of } \\
\text { stable and } \\
\text { compact char } \\
\text { layer }\end{array}$ & {$[36]$} \\
\hline $\begin{array}{l}\text { PLA/APP/PER (60/30/10) } \\
\text { PLA/APP/LIG (60/30/10) } \\
\text { PLA/APP/ST (60/30/10) }\end{array}$ & $\begin{array}{l}35 \\
35 \\
35\end{array}$ & $\begin{array}{l}3 \\
3 \\
3\end{array}$ & $\begin{array}{l}117(-64) \\
173(-46.77) \\
193(-40.62)\end{array}$ & $\begin{array}{l}\text { N/A } \\
\text { N/A } \\
\text { N/A }\end{array}$ & $\begin{array}{l}75(+4.17) \\
87(+20.83) \\
93(+29.17)\end{array}$ & $\begin{array}{l}\text { Formation of } \\
\text { intumescent } \\
\text { char layer }\end{array}$ & [41] \\
\hline $\begin{array}{l}\text { PLA/IFR (75/25) } \\
\quad(\text { IFR = APP/PER/MC) } \\
\text { PLA/IFR/ZnAl-LDH (75/23/2) }\end{array}$ & $\begin{array}{l}35 \\
35 \\
\end{array}$ & 3 & $\begin{array}{l}152(-65.14) \\
166(-61.93)\end{array}$ & $\begin{array}{l}87(-42.76) \\
35(-76.97)\end{array}$ & $\begin{array}{l}91(+37.88) \\
76(-15.15) \\
\end{array}$ & $\begin{array}{l}\text { Formation of } \\
\text { intumescent } \\
\text { char layer }\end{array}$ & [94] \\
\hline $\begin{array}{l}\text { PLA/APP }(85 / 15) \\
\text { PLA/APP/EG }(85 / 3.75 / 11.25)\end{array}$ & $\begin{array}{l}35 \\
35\end{array}$ & $\begin{array}{l}3 \\
3\end{array}$ & $\begin{array}{l}208.4(-23.38) \\
167.9(-38.27)\end{array}$ & $\begin{array}{l}46.1(-29.73) \\
46.9(-28.51)\end{array}$ & $\begin{array}{l}70(+16.67) \\
71(+18.33)\end{array}$ & $\begin{array}{l}\text { Formation of } \\
\text { intumescent } \\
\text { char layer }\end{array}$ & [76] \\
\hline $\begin{array}{l}\text { PLA/APP }(77 / 23) \\
\text { PLA/APP/LIG (77/18.4/4.6) } \\
\text { PLA/APP/UM-Lig } \\
\quad(77 / 18.4 / 4.6)\end{array}$ & $\begin{array}{l}35 \\
35 \\
35\end{array}$ & $\begin{array}{l}3 \\
3 \\
3\end{array}$ & $\begin{array}{l}340(-18.27) \\
150(-63.94) \\
105(-74.76)\end{array}$ & $\begin{array}{l}61(-14.08) \\
41(-42.25) \\
24(-66.2)\end{array}$ & $\begin{array}{l}12(-69.23) \\
26(-33.33) \\
37(-5.13)\end{array}$ & $\begin{array}{l}\text { Formation of } \\
\text { intumescent } \\
\text { char layer }\end{array}$ & {$[40]$} \\
\hline $\begin{array}{l}\text { PLA/APP/PER }(85 / 11.25 / 3.75) \\
\text { PLA/APP/NFC }(85 / 11.25 / 3.75) \\
\text { PLA/APP/PNFC } \\
\quad(85 / 11.25 / 3.75)\end{array}$ & $\begin{array}{l}35 \\
35 \\
35\end{array}$ & $\begin{array}{l}3 \\
3 \\
3\end{array}$ & $\begin{array}{l}362(-37.37) \\
358(-38.06) \\
313(-45.85)\end{array}$ & $\begin{array}{r}57.4(-20.61) \\
58(-19.78) \\
59.5(-17.7)\end{array}$ & $\begin{array}{l}62(+6.9) \\
55(-5.17) \\
48(-17.24)\end{array}$ & $\begin{array}{l}\text { Formation of } \\
\text { intumescent } \\
\text { char layer }\end{array}$ & {$[45]$} \\
\hline $\begin{array}{l}\text { PLA/AHP }(80 / 20) \\
\text { PLA/EG }(80 / 20) \\
\text { PLA/AHP/EG }(80 / 15 / 5)\end{array}$ & $\begin{array}{l}35 \\
35 \\
35\end{array}$ & $\begin{array}{l}3 \\
3 \\
3\end{array}$ & $\begin{array}{l}258(-48.09) \\
356(-35.15) \\
260(-52.64)\end{array}$ & $\begin{array}{l}57.7(-7.23) \\
43.5(-30.06) \\
49.8(-19.94) \\
\end{array}$ & $\begin{array}{l}41(-28.07) \\
46(-19.3) \\
54(-5.26)\end{array}$ & $\begin{array}{l}\text { Formation of } \\
\text { intumescent } \\
\text { char layer }\end{array}$ & [54] \\
\hline $\begin{array}{l}\text { PLA/APP/MA/CD }(80 / 10 / 5 / 5) \\
\text { PLA/APP/MA/PPG/CD } \\
\quad(80 / 10 / 5 / 0.75 / 4.25) \\
\text { PLA/APP/MA/PPR }(80 / 10 / 5 / 5)\end{array}$ & $\begin{array}{l}35 \\
35\end{array}$ & $\begin{array}{l}3 \\
3\end{array}$ & $\begin{array}{l}226(-65.65) \\
203(-69.15)\end{array}$ & $\begin{array}{r}49.6(-4.43) \\
48(-7.51) \\
43.1(-16.96)\end{array}$ & $\begin{array}{l}55(-8.33) \\
55(-8.33) \\
45(-25)\end{array}$ & $\begin{array}{l}\text { Formation of } \\
\text { intumescent } \\
\text { char layer }\end{array}$ & [43] \\
\hline $\begin{array}{l}\text { PLA/AHP }(90 / 10) \\
\text { PLA/IFR }(90 / 10) \\
\quad(\text { IFR }=\text { APP/PER }) \\
\text { PLA/AHP/IFR }(90 / 7 / 3)\end{array}$ & $\begin{array}{l}35 \\
35\end{array}$ & $\begin{array}{l}3 \\
3\end{array}$ & $\begin{array}{l}279.9(-35.24) \\
356.4(-17.54)\end{array}$ & $\begin{array}{r}98.6(+4.67) \\
116.9(+24.1) \\
92.3(-2.02) \\
\end{array}$ & $\begin{array}{r}66(-31.25) \\
119(+23.96) \\
81(-15.63) \\
\end{array}$ & $\begin{array}{l}\text { Formation of } \\
\text { intumescent } \\
\text { char layer }\end{array}$ & {$[80]$} \\
\hline $\begin{array}{l}\text { PLA/P-AA }(99.5 / 0.5) \\
\text { PLA/P-AA }(99 / 1)\end{array}$ & $\begin{array}{l}35 \\
35\end{array}$ & $\begin{array}{l}4 \\
4\end{array}$ & $\begin{array}{l}366(-16.25) \\
366(-16.25)\end{array}$ & $\begin{array}{l}90.5(-6.02) \\
87.2(-9.35)\end{array}$ & $\begin{array}{c}69(-4.55) \\
111(+68.18)\end{array}$ & $\begin{array}{l}\text { Induce incom- } \\
\text { plete combus- } \\
\text { tion in gas } \\
\text { phase }\end{array}$ & [67] \\
\hline $\begin{array}{l}\text { PLA/Gra }(99 / 1) \\
\text { PLA/IL }(97 / 3) \\
\text { PLA/GIL }(96 / 4)\end{array}$ & $\begin{array}{l}35 \\
35 \\
35\end{array}$ & $\begin{array}{l}4 \\
4 \\
4\end{array}$ & $\begin{array}{r}214(-33.95) \\
168(-48.15) \\
99(-69.44)\end{array}$ & $\begin{array}{l}46(-6.12) \\
43(-12.25) \\
33(-32.65)\end{array}$ & $\begin{array}{l}79(-10.23) \\
50(-43.18) \\
56(-36.36)\end{array}$ & $\begin{array}{l}\text { Formation of } \\
\text { stable and } \\
\text { compact char } \\
\text { layer }\end{array}$ & [59] \\
\hline
\end{tabular}


Tabla 4. Continuous.

\begin{tabular}{|c|c|c|c|c|c|c|c|}
\hline \multirow[b]{2}{*}{$\begin{array}{l}\text { Material designations and } \\
\text { composition }\end{array}$} & \multicolumn{5}{|c|}{ Combustion properties } & \multirow[b]{2}{*}{ Explanations } & \multirow[b]{2}{*}{ Ref. } \\
\hline & $\begin{array}{c}\text { Heat flux } \\
{\left[\mathrm{kW} / \mathrm{m}^{2}\right]}\end{array}$ & $\begin{array}{l}\text { Thickness } \\
\text { [mm] }\end{array}$ & $\begin{array}{c}\text { PHRR } \\
{\left[\mathrm{kW} / \mathrm{m}^{2}\right]} \\
(\% \text { of change })\end{array}$ & $\begin{array}{c}\text { THR } \\
{\left[\mathrm{MJ} / \mathrm{m}^{2}\right]} \\
(\% \text { of change })\end{array}$ & $\begin{array}{c}\text { TTI } \\
{[s]} \\
(\% \text { of change })\end{array}$ & & \\
\hline $\begin{array}{l}\text { PLA/MWNT }(95 / 5) \\
\text { PLA/IP }(95 / 5) \\
\text { PLA/MIP }(95 / 5)\end{array}$ & $\begin{array}{l}35 \\
35 \\
35\end{array}$ & $\begin{array}{l}4 \\
4 \\
4\end{array}$ & $\begin{array}{l}176(-45.68) \\
240(-25.93) \\
155(-52.16)\end{array}$ & $\begin{array}{l}47(-4.08) \\
46(-6.12) \\
34(-30.61)\end{array}$ & $\begin{array}{l}95(+7.95) \\
62(-29.55) \\
71(-19.32)\end{array}$ & $\begin{array}{l}\text { Formation of } \\
\text { stable and } \\
\text { compact char } \\
\text { layer }\end{array}$ & {$[60]$} \\
\hline $\begin{array}{l}\text { PLA/Al-Phyt/MCC }(80 / 10 / 10) \\
\text { PLA/Al-Phyt/NCC }(80 / 10 / 10) \\
\text { PLA/MCC-P }(80 / 20) \\
\text { PLA/Al-Phyt/MCC-P }(80 / 10 / 10)\end{array}$ & $\begin{array}{l}35 \\
35 \\
35 \\
35\end{array}$ & $\begin{array}{l}4 \\
4 \\
4 \\
4\end{array}$ & $\begin{array}{l}330(-15.38) \\
240(-38.46) \\
330(-15.38) \\
260(-33.33)\end{array}$ & $\begin{array}{l}81(-11.96) \\
76(-17.39) \\
84(-8.7) \\
80(-13.04) \\
\end{array}$ & $\begin{array}{l}43(-50) \\
61(-29.07) \\
46(-46.51) \\
66(-23.26) \\
\end{array}$ & $\begin{array}{l}\text { Formation of } \\
\text { stable and } \\
\text { compact char } \\
\text { layer }\end{array}$ & [81] \\
\hline PLA/PPLA & 35 & 6 & $337(-21.38)$ & N/A & $78(+68.18)$ & Char formation & {$[70]$} \\
\hline $\begin{array}{l}\text { PLA/HNT }(83 / 17) \\
\text { PLA/HNT-W (83/17) }\end{array}$ & $\begin{array}{l}50 \\
50\end{array}$ & $\begin{array}{l}3 \\
3\end{array}$ & $\begin{array}{l}298(-28.88) \\
242(-42.24)\end{array}$ & $\begin{array}{r}56(-6.67) \\
49.5(-17.5)\end{array}$ & $\begin{array}{l}28(-3.45) \\
27(-6.9)\end{array}$ & $\begin{array}{l}\text { Formation of } \\
\text { silicate rich } \\
\text { char layer }\end{array}$ & [51] \\
\hline $\begin{array}{l}\text { PLA/EG }(99 / 1) \\
\text { PLA/EG }(90 / 10)\end{array}$ & $\begin{array}{l}50 \\
50\end{array}$ & $\begin{array}{l}3 \\
3\end{array}$ & $\begin{array}{l}410(-3.53) \\
305(-28.24)\end{array}$ & $\begin{array}{l}70(-9.38) \\
52(-18.75)\end{array}$ & $\begin{array}{l}44(-31.25) \\
60(-6.25)\end{array}$ & $\begin{array}{l}\text { Formation of } \\
\text { intumescent } \\
\text { char layer }\end{array}$ & {$[55]$} \\
\hline $\begin{array}{l}\text { PLA/APP/TT2 }(70 / 25 / 5) \\
\text { PLA/APP/TT4 }(70 / 25 / 5)\end{array}$ & $\begin{array}{l}50 \\
50\end{array}$ & $\begin{array}{l}3 \\
3\end{array}$ & $\begin{array}{l}243.89(-64.42) \\
181.53(-73.52)\end{array}$ & $\begin{array}{l}47.16(-19.33) \\
41.05(-29.78)\end{array}$ & $\begin{array}{l}\text { N/A } \\
\text { N/A }\end{array}$ & $\begin{array}{l}\text { Formation of } \\
\text { intumescent } \\
\text { char layer }\end{array}$ & {$[46]$} \\
\hline PLA/Sep/MWNT (88/10/2) & 50 & 5 & $265(-45.36)$ & $115(+10.57)$ & N/A & $\begin{array}{l}\text { Formation of } \\
\text { silicate rich } \\
\text { char layer }\end{array}$ & {$[53]$} \\
\hline $\begin{array}{l}\text { PLA/Ni }(95 / 5) \\
\text { PLA/Si }(95 / 5) \\
\text { PLA/Si/Ni }(90 / 5 / 5)\end{array}$ & $\begin{array}{l}50 \\
50 \\
50\end{array}$ & $\begin{array}{l}6 \\
6 \\
6\end{array}$ & $\begin{array}{l}401(-10.49) \\
442(-1.34) \\
249(-44.42)\end{array}$ & $\begin{array}{c}123(-2.38) \\
117(-7.14) \\
87(-30.95)\end{array}$ & $\begin{array}{l}46(+2.22) \\
45(0) \\
44(-2.22)\end{array}$ & $\begin{array}{l}\text { Formation of } \\
\text { stable and } \\
\text { compact char } \\
\text { layer }\end{array}$ & [77] \\
\hline $\begin{array}{l}\text { PLA/ATH/C30B }(60 / 35 / 5) \\
\text { PLA/ATH/C30B }(50 / 45 / 5) \\
\text { PLA/ATH }(70 / 30) \\
\text { PLA/ATH }(60 / 40)\end{array}$ & $\begin{array}{l}50 \\
50 \\
50 \\
50\end{array}$ & $\begin{array}{l}6 \\
6 \\
6 \\
6\end{array}$ & $\begin{array}{c}252(-59.9) \\
221.5(-64.76) \\
443.8(-29.39) \\
411.8(-34.48)\end{array}$ & $\begin{array}{l}\text { N/A } \\
\text { N/A } \\
\text { N/A } \\
\text { N/A }\end{array}$ & $\begin{array}{c}65(+12.07) \\
64(-10.34) \\
75(+29.31) \\
142(+144.83)\end{array}$ & $\begin{array}{l}\text { Formation of } \\
\text { stable and } \\
\text { compact char } \\
\text { layer }\end{array}$ & [87] \\
\hline
\end{tabular}

sites on the external surface of clay after degradation of the organophilic modifier $[98,99]$. Table 4 suggests that the combined use of sepiolite and MWNT could generate the highest PHRR reduction (i.e., 45\%) among all the silicate-type additives.

The formation of a stable and compact carbonized char layer by conventional FRs in the presence of micro-and nanofillers decreased the PHRR and THR of combustion by 33-69 and 13-33\%, respectively. The combined use of conventional FRs and synergists often give better performance than their separate use, where a PHRR reduction of merely $26-55 \%$ and a THR reduction of $6-12 \%$ were found. A possible explanation for this finding can be related to changes in carbonaceous char. The char layer, generated by conventional FRs, was reinforced by micro- and nanoscale additives (e.g., graphene, MWNT, and NCC). It was a surprising finding that PLA/GIL exhibited a reduction of 69 and $32 \%$ in the PHRR and THR, respectively, at a loading of merely $4 \mathrm{wt} \%$ GIL.
Among all the formulations, intumescent char layers, produced by the majority of intumescent flame retardants, yielded the maximum depression in the PHRR (i.e., 35-75\%) and THR (i.e., 17-30\%). Accordingly, intumescent char layers offer powerful thermal protection that limits heat penetration and mass transfer through the porous and (partly) closed cell structured char. This is well reflected in excellent performance based on CCM evaluation. From Table 4, PLA/APP/ UM-Lig displays a maximum reduction in PHRR (i.e., 75\%) while PLA/IFR/ZnAl-LDH shows excellent performance in terms of THR (with a reduction of $77 \%$ ). It is worth mentioning that APP remains a necessary additive in IFR formulations as it decreases PHRR and THR values during PLA combustion. Furthermore, the coexistence of gas and condensed phase mechanisms in PLA combustion may significantly prolong the initial combustion time along with a $52 \%$ loss in the PHRR, as observed for example for the formulation PLA/SPB-100/EG. 


\section{Conclusions}

Based on this review, the combined use of flame retardants seems to be one of the promising strategies in the near future to produce PLA systems with improved fire performance. Through synergistic interaction between suitable flame retardant additives, lower amount of these compounds are needed, which is highly beneficial for maintaining other properties, including processability. One of the main problems when developing FR-PLA is the stability of PLA during processing. Thus, monitoring the molecular weight and mechanical properties changes during the processing of FR-PLA should be taking into consideration. The limitations of currently available flame retardants could be overcome either by synthesizing new compounds, or hybridizing or chemically modifying existing flame retardants. For the synthesis of novel phosphorous-containing flame retardants, biobased platform chemicals will be extensively explored. The potential of materials from renewable resources (such as starch, cellulose, lignin, $\beta$-cyclodextrin) in intumescent formulations will be a preferred research topic. Encapsulation techniques of flame retardants, which improve compatibility with the PLA matrix will also spread. This review can be a useful reference for researchers and engineers to formulate and design flame retarded PLAs according to the needs of the respective applications.

\section{Acknowledgements}

The authors would like to express their appreciation to Universiti Sains Malaysia for Research University Grant (grant number; 814199) and Ministry of Higher Education for Fundamental Research Grant Scheme (grant number; 6071260). Part of the work was supported by the Hungarian Scientific Research Fund (OTKA 109409).

\section{References}

[1] Mehta R., Kumar V., Bhunia H., Upadhyay S. N.: Synthesis of poly(lactic acid): A review. Journal of Macromolecular Science Part C, 45, 325-349 (2005). https://doi.org/10.1080/15321790500304148

[2] Södergård A., Stolt M.: Properties of lactic acid based polymers and their correlation with composition. Progress in Polymer Science, 27, 1123-1163 (2002). https://doi.org/10.1016/S0079-6700(02)00012-6

[3] Rasal R. M., Janorkar A. V., Hirt D. E.: Poly(lactic acid) modifications. Progress in Polymer Science, 35, 338356 (2010).

https://doi.org/10.1016/j.progpolymsci.2009.12.003
[4] Gupta B., Revagade N., Hilborn J.: Poly(lactic acid) fiber: An overview. Progress in Polymer Science, 32, 455-482 (2007).

https://doi.org/10.1016/j.progpolymsci.2007.01.005

[5] Hamad K., Kaseem M., Yang H. W., Deri F., Ko Y. G.: Properties and medical applications of polylactic acid: A review. Express Polymer Letters, 9, 435-455 (2015). https://doi.org/10.3144/expresspolymlett.2015.42

[6] Chow W. S., Lok S. K.: Thermal properties of poly(lactic acid)/organo-montmorillonite nanocomposites. Journal of Thermal Analysis and Calorimetry, 95, 627-632 (2009).

https://doi.org/10.1007/s10973-007-8975-x

[7] Leu Y. Y., Mohd Ishak Z. A., Chow W. S.: Mechanical, thermal, and morphological properties of injection molded poly(lactic acid)/SEBS- $g$-MAH/organo-montmorillonite nanocomposites. Journal of Applied Polymer Science, 124, 1200-1207 (2011).

https://doi.org/10.1002/app.35084

[8] Balakrishnan H., Hassan A., Imran M., Wahit M. U.: Toughening of polylactic acid nanocomposites: A short review. Polymer-Plastics Technology and Engineering, 51, 175-192 (2012). https://doi.org/10.1080/03602559.2011.618329

[9] Ruellan A., Guinault A., Sollogoub C., Chollet G., AitMada A., Ducruet V., Domenek S.: Industrial vegetable oil by-products increase the ductility of polylactide. Express Polymer Letters, 9, 1087-1103 (2015).

https://doi.org/10.3144/expresspolymlett.2015.98

[10] Rashmi B. J., Prashantha K., Lacrampe M-F., Krawczak P.: Toughening of poly(lactic acid) without sacrificing stiffness and strength by melt-blending with polyamide 11 and selective localization of halloysite nanotubes. Express Polymer Letters, 9, 721-735 (2015). https://doi.org/10.3144/expresspolymlett.2015.67

[11] Saeidlou S., Huneault M. A., Li H., Park C. B.: Poly (lactic acid) crystallization. Progress in Polymer Science, 37, 1657-1677 (2012).

https://doi.org/10.1016/j.progpolymsci.2012.07.005

[12] Fehri M. K., Mugoni C., Cinelli P., Anguillesi I., Coltelli M. B., Fiori S., Montorsi M., Lazzeri A.: Composition dependence of the synergistic effect of nucleating agent and plasticizer in poly(lactic acid): A mixture design study. Express Polymer Letters, 10, 274-288 (2016). https://doi.org/10.3144/expresspolymlett.2016.26

[13] Maspoch M. L., Santana O. O., Cailloux J., FrancoUrquiza E., Rodriguez C., Belzunce J., Martínez A. B.: Ductile-brittle transition behaviour of PLA/o-MMT films during the physical aging process. Express Polymer Letters, 9, 185-195 (2015).

https://doi.org/10.3144/expresspolymlett.2015.20

[14] Vink E. T. H., Rábago K. R., Glassner D. A., Springs B., O’Connor R. P., Kolstad J., Gruber P. R.: The sustainability of NatureWorks ${ }^{\mathrm{TM}}$ polylactide polymers and Ingeo $^{\mathrm{TM}}$ polylactide fibers: An update of the future. Macromolecular Bioscience, 4, 551-564 (2004). https://doi.org/10.1002/mabi.200400023 
[15] Maharana T., Mohanty B., Negi Y. S.: Melt-solid polycondensation of lactic acid and its biodegradability. Progress in Polymer Science, 34, 99-124 (2009). https://doi.org/10.1016/j.progpolymsci.2008.10.001

[16] Shukor F., Hassan A., Hasan M., Islam M. S., Mokhtar M.: PLA/kenaf/APP biocomposites: Effect of alkali treatment and ammonium polyphosphate (APP) on dynamic mechanical and morphological properties. Polymer-Plastics Technology and Engineering, 53, 760-766 (2014). https://doi.org/10.1080/03602559.2013.869827

[17] Farrington D. W., Lunt J., Davies S., Blackburn R. S.: Poly(lactic acid) fibers. in 'Biodegradable and sustainable fibres' (ed.: Blackburn R. S.) Woodhead, Abingdon, 191-220 (2005).

[18] Pang X., Zhuang X., Tang Z., Chen X.: Polylactic acid (PLA): Research, development and industrialization. Biotechnology Journal, 5, 1125-1136 (2010). https://doi.org/10.1002/biot.201000135

[19] Auras R., Harte B., Selke S.: An overview of polylactides as packaging materials. Macromolecular Bioscience, 4, 835-864 (2004). https://doi.org/10.1002/mabi.200400043

[20] Vink E. T. H., Davies S., Kolstad J. J.: The eco-profile for current Ingeo ${ }^{\circledR}$ polylactide production. Industrial Biotechnology, 6, 213-224 (2010). https://doi.org/10.1089/ind.2010.6.212

[21] Vink E. T. H., Rábago K. R., Glassner D. A., Gruber P. R.: Applications of life cycle assessment to NatureWorks $^{\mathrm{TM}}$ polylactide (PLA) production. Polymer Degradation and Stability, 80, 403-419 (2003). https://doi.org/10.1016/S0141-3910(02)00372-5

[22] Rusu D., Boyer S. A. E., Lacrampe M. F., Krawczak P.: Bioplastics and vegetal fiber reinforced bioplastics for automotive applications. in 'Handbook of bioplastics and biocomposites engineering applications' (ed.: Pilla S.) Scrivener Publishing, Massachusetts, 397-449 (2011).

[23] Vink E. T. H., Glassner D. A., Kolstad J. J., Wooley R. J., O'Connor R. P.: The eco-profiles for current and nearfuture NatureWorks ${ }^{\circledR}$ polylactide (PLA) production. Industrial Biotechnology, 3, 58-81 (2007).

https://doi.org/10.1089/ind.2007.3.058

[24] Tehrani M. A., Akbari A., Majumder M.: Polylactic acid (PLA) layered silicate nanocomposites. in 'Handbook of polymer nanocomposites. Processing, performance, and application' (eds.: Pandey J. K., Reddy K. R., Mohanty A. K., Misra M.) Springer, Berlin, 53-67 (2014).

[25] Koskinen M.: Bag for a beverage preparation. U.S. Patent 20140227398 A1, USA (2014).

[26] Chang Y-N., Mueller R. E., Iannoti E. L.: Use of low MW polylactic acid and lactide to stimulate growth and yield of soybeans. Plant Growth Regulation, 19, 223 232 (1996).

https://doi.org/10.1007/BF00037795
[27] Obuchi S., Ogawa S.: Packaging and other commercial applications. in 'Poly(lactic acid): Synthesis, structures, properties, processing, and applications' (eds.: Auras R., Lim L-T., Selke S. E. M., Tsuji H.) Wiley, New York, 457-467 (2010).

https://doi.org/10.1002/9780470649848.ch28

[28] Domenek S., Courgneau C., Ducruet V.: Characteristics and applications of poly(lactide). in 'Biopolymers: biomedical and environmental applications' (eds.: Kalia S., Avérous L.) Wiley, New York, 183-224 (2011). https://doi.org/10.1002/9781118164792.ch8

[29] Kimura K., Horikoshi Y.: Bio-based polymers. Fujitsu Scientific and Technical Journal, 41, 173-180 (2005).

[30] Boyd S. B.: Bio-based versus conventional plastics for electronics housings: LCA literature review. The Sustainability Consortium, 101, 1-15 (2011).

[31] Babu R. P., O’Connor K., Seeram R.: Current progress on bio-based polymers and their future trends. Progress in Biomaterials, 2, 8/1-8/16 (2013). https://doi.org/10.1186/2194-0517-2-8.

[32] NEC Corporation.: Japanese company develops flame retardant bio-plastic. Plastics, Additives and Compounding, 6, 32 (2004). https://doi.org/10.1016/S1464-391X(04)00141-2

[33] Niaounakis M.: Biopolymers: Applications and trends. Elsevier, New York (2015).

[34] Bourbigot S., Fontaine G.: Flame retardancy of polylactide: An overview. Polymer Chemistry, 1, 14131422 (2010). https://doi.org/10.1039/c0py00106f

[35] Wei L-L., Wang D-Y., Chen H-B., Chen L., Wang X-L., Wang Y-Z.: Effect of a phosphorus-containing flame retardant on the thermal properties and ease of ignition of poly(lactic acid). Polymer Degradation and Stability, 96, 1557-1561 (2011). https://doi.org/10.1016/j.polymdegradstab.2011.05.018

[36] Tang G., Wang X., Zhang R., Wang B. B., Hong N. N., $\mathrm{Hu}$ Y., Song L., Gong X. L.: Effect of rare earth hypophosphite salts on the fire performance of biobased polylactide composites. Industrial and Engineering Chemistry Research, 52, 7362-7372 (2013).

https://doi.org/10.1021/ie302466k

[37] Tang G., Huang X., Ding H., Wang X., Jiang S., Zhou K., Wang B., Yang W., Hu Y.: Combustion properties and thermal degradation behaviors of biobased polylactide composites filled with calcium hypophosphite. RSC Advances, 4, 8985-8993 (2014). https://doi.org/10.1039/c3ra44537b

[38] Wang X., Hu Y., Song L., Xuan S., Xing W., Bai Z., Lu H.: Flame retardancy and thermal degradation of intumescent flame retardant poly(lactic acid)/starch biocomposites. Industrial and Engineering Chemistry Research, 50, 713-720 (2011). https://doi.org/10.1021/ie1017157 
[39] Feng C., Liang M., Jiang J., Huang J., Liu H.: Flame retardant properties and mechanism of an efficient intumescent flame retardant PLA composites. Polymers for Advanced Technologies, 27, 693-700 (2016). https://doi.org/10.1002/pat.3743

[40] Zhang R., Xiao X., Tai Q., Huang H., Hu Y.: Modification of lignin and its application as char agent in intumescent flame-retardant poly(lactic acid). Polymer Engineering and Science, 52, 2620-2626 (2012). https://doi.org/10.1002/pen.23214

[41] Réti C., Casetta M., Duquesne S., Bourbigot S., Delobel R.: Flammability properties of intumescent PLA including starch and lignin. Polymers for Advanced Technologies, 19, 628-635 (2008). https://doi.org/10.1002/pat.1130

[42] Feng J-X., Su S-P., Zhu J.: An intumescent flame retardant system using $\beta$-cyclodextrin as a carbon source in polylactic acid (PLA). Polymers for Advanced Technologies, 22, 1115-1122 (2011).

https://doi.org/10.1002/pat.1954

[43] Wang X., Xing W., Wang B., Wen P., Song L., Hu Y., Zhang P.: Comparative study on the effect of beta-cyclodextrin and polypseudorotaxane as carbon sources on the thermal stability and flame retardance of polylactic acid. Industrial and Engineering Chemistry Research, 52, 3287-3294 (2013). https://doi.org/10.1021/ie303002b

[44] Fox D. M., Temburni S., Novy M., Flynn L., Zammarano M., Kim Y. S., Gilman J. W., Davis R. D.: Thermal and burning properties of poly(lactic acid) composites using cellulose-based intumescing flame retardants. in 'Fire and polymers VI: New advances in flame retardant chemistry and science' (eds.: Morgan A. B., Wilkie C. A., Nelson G. L.) American Chemistry Society, Washington, 223-234 (2012).

[45] Fox D. M., Lee J., Citro C. J., Novy M.: Flame retarded poly(lactic acid) using POSS-modified cellulose. 1. Thermal and combustion properties of intumescing composites. Polymer Degradation and Stability, 98, 590-596 (2013).

https://doi.org/10.1016/j.polymdegradstab.2012.11.016

[46] Yuan S., Chen W., Liu G.: Effects of two kinds of THEIC-based charring agents on flame-retardant properties of polylactide. Journal of Applied Polymer Science, 132, 42086/1-42086/8 (2015).

https://doi.org/10.1002/app.42086

[47] Zhan J., Song L., Nie S., Hu Y.: Combustion properties and thermal degradation behavior of polylactide with an effective intumescent flame retardant. Polymer Degradation and Stability, 94, 291-296 (2009).

https://doi.org/10.1016/j.polymdegradstab.2008.12.015

[48] Ke C-H., Li J., Fang K-Y., Zhu Q-L., Zhu J., Yan Q., Wang Y-Z.: Synergistic effect between a novel hyperbranched charring agent and ammonium polyphosphate on the flame retardant and anti-dripping properties of polylactide. Polymer Degradation and Stability, 95, 763-770 (2010).

https://doi.org/10.1016/j.polymdegradstab.2010.02.011
[49] Rhim J-W., Park H-M., Ha C-S.: Bio-nanocomposites for food packaging applications. Progress in Polymer Science, 38, 1629-1652 (2013). https://doi.org/10.1016/j.progpolymsci.2013.05.008

[50] Reddy M. M., Vivekanandhan S., Misra M., Bhatia S. K., Mohanty A. K.: Biobased plastics and bionanocomposites: Current status and future opportunities. Progress in Polymer Science, 38, 1653-1689 (2013). https://doi.org/10.1016/j.progpolymsci.2013.05.006

[51] Stoclet G., Sclavons M., Lecouvet B., Devaux J., Van Velthem P., Boborodea A., Bourbigot S., Sallem-Idrissi N.: Elaboration of poly(lactic acid)/halloysite nanocomposites by means of water assisted extrusion: structure, mechanical properties and fire performance. RSC Advances, 4, 57553-57563 (2014).

https://doi.org/10.1039/C4RA06845A

[52] Bourbigot S., Fontaine G., Gallos A., Bellayer S.: Reactive extrusion of PLA and of PLA/carbon nanotubes nanocomposite: Processing, characterization and flame retardancy. Polymers for Advanced Technologies, 22, 30-37 (2010).

https://doi.org/10.1002/pat.1715

[53] Hapuarachchi T. D., Peijs T.: Multiwalled carbon nanotubes and sepiolite nanoclays as flame retardants for polylactide and its natural fibre reinforced composites. Composites Part A: Applied Science and Manufacturing, 41, 954-963 (2010). https://doi.org/10.1016/j.compositesa.2010.03.004

[54] Tang G., Zhang R., Wang X., Wang B., Song L., Hu Y., Gong X.: Enhancement of flame retardant performance of bio-based polylactic acid composites with the incorporation of aluminum hypophosphite and expanded graphite. Journal of Macromolecular Science Part A: Pure and Applied Chemistry, 50, 255-269 (2013). https://doi.org/10.1080/10601325.2013.742835

[55] Wei P., Bocchini S., Camino G.: Flame retardant and thermal behavior of polylactide/expandable graphite composites. Polimery, 58, 361-364 (2013). https://doi.org/10.14314/polimery.2013.361

[56] Bourbigot S., Fontaine G., Gallos A., Gérard C., Bellayer S.: Functionalized-carbon multiwall nanotube as flame retardant for polylactic acid. in 'Fire and polymers V: Materials and concepts for fire retardancy' (eds.: Wilkie C. A., Morgan A. B., Nelson G. L.) American Chemistry Society, Washington, 25-34 (2009). https://doi.org/10.1021/bk-2009-1013.ch003

[57] Murariu M., Bonnaud L., Yoann P., Fontaine G., Bourbigot S., Dubois P.: New trends in polylactide (PLA)based materials: 'Green' PLA-calcium sulfate (nano)composites tailored with flame retardant properties. Polymer Degradation and Stability, 95, 374-381 (2010). https://doi.org/10.1016/j.polymdegradstab.2009.11.032

[58] Karger-Kocsis J., Kmetty Á., Lendvai L., Drakopoulos S. X., Bárány T.: Water-assisted production of thermoplastic nanocomposites: A review. Materials, 8, 72-95 (2015). https://doi.org/10.3390/ma8010072 
[59] Gui H., Xu P., Hu Y., Wang J., Yang X., Bahader A., Ding Y.: Synergistic effect of graphene and an ionic liquid containing phosphonium on the thermal stability and flame retardancy of polylactide. RSC Advances, 5, 27814-27822 (2015).

https://doi.org/10.1039/C4RA16393A

[60] Hu Y., Xu P., Gui H., Wang X., Ding Y.: Effect of imidazolium phosphate and multiwalled carbon nanotubes on thermal stability and flame retardancy of polylactide. Composites Part A: Applied Science and Manufacturing, 77, 147-153 (2015). https://doi.org/10.1016/j.compositesa.2015.06.025

[61] Ju Y., Wang T., Huang Y., Zhou L., Yang Y., Liao F., Wang X.: The flame-retardance polylactide nanocomposites with nano attapulgite coated by resorcinol bis (diphenyl phosphate). Journal of Vinyl Additives and Technology, 22, 506-513 (2016). https://doi.org/10.1002/vnl.21469

[62] Liu J., Zhou K., Wen P., Wang B., Hu Y., Gui Z.: The influence of multiple modified MMT on the thermal and fire behavior of poly (lactic acid) nanocomposites. Polymers for Advanced Technologies, 26, 626-634 (2015). https://doi.org/10.1002/pat.3497

[63] Tao K., Li J., Xu L., Zhao X., Xue L., Fan X., Yan Q.: A novel phosphazene cyclomatrix network polymer: Design, synthesis and application in flame retardant polylactide. Polymer Degradation and Stability, 96, 1248 1254 (2011).

https://doi.org/10.1016/j.polymdegradstab.2011.04.011

[64] Xi W., Qian L., Qiu Y., Chen Y.: Flame-retardant behavior of bi-group molecule derived from phosphaphenanthrene and triazine groups on polylactic acid. Polymers for Advanced Technologies, 27, 781-788 (2016). https://doi.org/10.1002/pat.3714

[65] Lin H-J., Liu S-R., Han L-J., Wang X-M., Bian Y-J., Dong L-S.: Effect of a phosphorus-containing oligomer on flame-retardant, rheological and mechanical properties of poly(lactic acid). Polymer Degradation and Stability, 98, 1389-1396 (2013).

https://doi.org/10.1016/j.polymdegradstab.2013.03.025

[66] Lin H., Han L., Dong L.: Thermal degradation behavior and gas phase flame-retardant mechanism of polylactide/ PCPP blends. Journal of Applied Polymer Science, 131, 40480/1-40480/11 (2014).

https://doi.org/10.1002/app.40480

[67] Zhao X., Guerrero F. R., Llorca J., Wang D-Y.: New superefficiently flame-retardant bioplastic poly(lactic acid): Flammability, thermal decomposition behavior, and tensile properties. ACS Sustainable Chemistry and Engineering, 4, 202-209 (2016).

https://doi.org/10.1021/acssuschemeng.5b00980

[68] Jing J., Zhang Y., Tang X., Fang Z.: Synthesis of a highly efficient phosphorus-containing flame retardant utilizing plant-derived diphenolic acids and its application in polylactic acid. RSC Advances, 6, 49019-49027 (2016).

https://doi.org/10.1039/C6RA06742E
[69] Chang S., Zeng C., Yuan W., Ren J.: Preparation and characterization of double-layered microencapsulated red phosphorus and its flame retardance in poly(lactic acid). Journal of Applied Polymer Science, 125, 30143022 (2012).

https://doi.org/10.1002/app.36449

[70] Wang D-Y., Song Y-P., Lin L., Wang X-L., Wang Y-Z.: A novel phosphorus-containing poly(lactic acid) toward its flame retardation. Polymer, 52, 233-238 (2011). https://doi.org/10.1016/j.polymer.2010.11.023

[71] Yuan X-Y., Wang D-Y., Chen L., Wang X-L., Wang YZ.: Inherent flame retardation of bio-based poly(lactic acid) by incorporating phosphorus linked pendent group into the backbone. Polymer Degradation and Stability, 96, 1669-1675 (2011).

https://doi.org/10.1016/j.polymdegradstab.2011.06.012

[72] Qian Y., Wei P., Jiang P., Zhao X., Yu H.: Synthesis of a novel hybrid synergistic flame retardant and its application in PP/IFR. Polymer Degradation and Stability, 96, 1134-1140 (2011).

https://doi.org/10.1016/j.polymdegradstab.2011.02.017

[73] Cao Y., Ju Y., Liao F., Jin X., Dai X., Li J., Wang X.: Improving the flame retardancy and mechanical properties of poly(lactic acid) with a novel nanorod-shaped hybrid flame retardant. RSC Advances, 6, 1485214858 (2016). https://doi.org/10.1039/C5RA25112E

[74] Qian Y., Wei P., Jiang P., Li Z., Yan Y., Ji K.: Aluminated mesoporous silica as novel high-effective flame retardant in polylactide. Composites Science and Technology, 82, 1-7 (2013).

https://doi.org/10.1016/j.compscitech.2013.03.019

[75] Vuorinen E., Nhlapo N., Mafa T., Karger-Kocsis J.: Thermooxidative degradation of LDPE nanocomposites: Effect of surface treatments of fumed silica and boehmite alumina. Polymer Degradation and Stability, 98, 2297-2305 (2013).

https://doi.org/10.1016/j.polymdegradstab.2013.08.011

[76] Zhu H., Zhu Q., Li J., Tao K., Xue L., Yan Q.: Synergistic effect between expandable graphite and ammonium polyphosphate on flame retarded polylactide. Polymer Degradation and Stability, 96, 183-189 (2011). https://doi.org/10.1016/j.polymdegradstab.2010.11.017

[77] Gong J., Tian N., Wen X., Chen X., Liu J., Jiang Z., Mijowska E., Tang T.: Synergistic effect of fumed silica with $\mathrm{Ni}_{2} \mathrm{O}_{3}$ on improving flame retardancy of poly(lactic acid). Polymer Degradation and Stability, 104, 18-27 (2014).

https://doi.org/10.1016/j.polymdegradstab.2014.03.030

[78] Kiuchi Y., Iji M., Yanagisawa T., Shukichi T.: Flameretarding polylactic-acid composite formed by dual use of aluminum hydroxide and phenol resin. Polymer Degradation and Stability, 109, 336-342 (2014). https://doi.org/10.1016/j.polymdegradstab.2013.05.013 
[79] Mu X., Yuan B., Hu W., Qiu S., Song L., Hu Y.: Flame retardant and anti-dripping properties of polylactic acid/poly(bis(phenoxy)phosphazene)/expandable graphite composite and its flame retardant mechanism. RSC Advances, 5, 76068-76078 (2015).

https://doi.org/10.1039/C5RA12701G

[80] Zhou X., Li J., Wu Y.: Synergistic effect of aluminum hypophosphite and intumescent flame retardants in polylactide. Polymers for Advanced Technologies, 26, 255265 (2015). https://doi.org/10.1002/pat.3451

[81] Costes L., Laoutid F., Khelifa F., Rose G., Brohez S., Delvosalle C., Dubois P.: Cellulose/phosphorus combinations for sustainable fire retarded polylactide. European Polymer Journal, 74, 218-228 (2016). https://doi.org/10.1016/j.eurpolymj.2015.11.030

[82] Zhou L., Ju Y., Liao F., Yang Y., Wang X.: Improve the mechanical property and flame retardant efficiency of the composites of poly(lactic acid) and resorcinol di (phenyl phosphate) (RDP) with $\mathrm{ZnO}$-coated kenaf. Fire and Materials, 40, 129-140 (2016).

https://doi.org/10.1002/fam.2274

[83] Graupner N., Albrecht K., Ziegmann G., Enzler H., Müssig J.: Influence of reprocessing on fibre length distribution, tensile strength and impact strength of injection moulded cellulose fibre-reinforced polylactide (PLA) composites. Express Polymer Letters, 10, 647663 (2016).

https://doi.org/10.3144/expresspolymlett.2016.59

[84] Wei P., Bocchini S., Camino G.: Nanocomposites combustion peculiarities. A case history: Polylactide-clays. European Polymer Journal, 49, 932-939 (2013).

https://doi.org/10.1016/j.eurpolymj.2012.11.010

[85] González A., Dasari A., Herrero B., Plancher E., Santarén J., Esteban A., Lim S-H.: Fire retardancy behavior of PLA based nanocomposites. Polymer Degradation and Stability, 97, 248-256 (2012).

https://doi.org/10.1016/j.polymdegradstab.2011.12.021

[86] Weil E. D., Levchik S. V.: Flame retardants for plastics and textiles practical applications. Hanser, Munich (2009).

https://doi.org/10.3139/9783446430655

[87] Cheng K-C., Yu C-B., Guo W., Wang S-F., Chuang T-H., Lin Y-H.: Thermal properties and flammability of polylactide nanocomposites with aluminum trihydrate and organoclay. Carbohydrate Polymers, 87, 1119-1123 (2012).

https://doi.org/10.1016/j.carbpol.2011.08.065

[88] Bocz K., Domonkos M., Igricz T., Kmetty Á., Bárány T., Marosi G.: Flame retarded self-reinforced poly(lactic acid) composites of outstanding impact resistance. Composites Part A: Applied Science and Manufacturing, 70, 27-34 (2015).

https://doi.org/10.1016/j.compositesa.2014.12.005

[89] Karger-Kocsis J., Bárány T.: Single-polymer composites (SPCs): Status and future trends. Composites Science Technology, 92, 77-94 (2014).

https://doi.org/10.1016/j.compscitech.2013.12.006
[90] Bocz K., Szolnoki B., Marosi A., Tábi T., WladykaPrzybylak M., Marosi G.: Flax fibre reinforced PLA/TPS biocomposites flame retarded with multifunctional additive system. Polymer Degradation and Stability, 106, 63-73 (2014).

https://doi.org/10.1016/j.polymdegradstab.2013.10.025

[91] Chow W. S., Teoh E. L.: Flexible and flame resistant poly(lactic acid)/organomontmorillonite nanocomposites. Journal of Applied Polymer Science, 132, 41253/141253/11 (2015). https://doi.org/10.1002/app.41253

[92] Fontaine G., Bourbigot S.: Intumescent polylactide: A nonflammable material. Journal of Applied Polymer Science, 113, 3860-3865 (2009). https://doi.org/10.1002/app.30379

[93] Li S., Yuan H., Yu T., Yuan W., Ren J.: Flame-retardancy and anti-dripping effects of intumescent flame retardant incorporating montmorillonite on poly(lactic acid). Polymers for Advanced Technologies, 20, 1114-1120 (2009). https://doi.org/10.1002/pat.1372

[94] Wang D-Y., Leuteritz A., Wang Y-Z., Wagenknecht U., Heinrich G.: Preparation and burning behaviors of flame retarding biodegradable poly(lactic acid) nanocomposite based on zinc aluminum layered double hydroxide. Polymer Degradation and Stability, 95, 2474-2480 (2010). https://doi.org/10.1016/j.polymdegradstab.2010.08.007

[95] Song L., Xuan S., Wang X., Hu Y.: Flame retardancy and thermal degradation behaviors of phosphate in combination with POSS in polylactide composites. Thermochimica Acta, 527, 1-7 (2012). https://doi.org/10.1016/j.tca.2011.07.012

[96] Zhan J., Wang L., Hong N., Hu W., Wang J., Song L., $\mathrm{Hu}$ Y.: Flame-retardant and anti-dripping properties of intumescent flame-retardant polylactide with different synergists. Polymer-Plastics Technology and Engineering, 53, 387-394 (2014). https://doi.org/10.1080/03602559.2013.844826

[97] Dasari A., Yu Z-Z., Cai G-P., Mai Y-W.: Recent developments in the fire retardancy of polymeric materials. Progress in Polymer Science, 38, 1357-1387 (2013). https://doi.org/10.1016/j.progpolymsci.2013.06.006

[98] Kiliaris P., Papasyrides C. D.: Polymer/layered silicate (clay) nanocomposites: An overview of flame retardancy. Progress in Polymer Science, 35, 902-958 (2010). https://doi.org/10.1016/j.progpolymsci.2010.03.001

[99] Tham W. L., Poh B. T., Mohd Ishak Z. A., Chow W. S.: Thermal behaviors and mechanical properties of halloysite nanotube-reinforced poly(lactic acid) nanocomposites. Journal of Thermal Analysis and Calorimetry, 118, 1639-1647 (2014). https://doi.org/10.1007/s10973-014-4062-2 